\title{
UTILIZATION OF PLANTAGO, PECTIN AND COMPRITOL FOR THE PRODUCTION OF SUSTAINED RELEASE TRAMADOL MATRIX TABLETS BY DIRECT COMPRESSION
}

Adel M. Aly, Sara A.M.Aly and Raslan H. M. Kittaneh

College of Pharmacy, Alisra University, Amman, Jordan

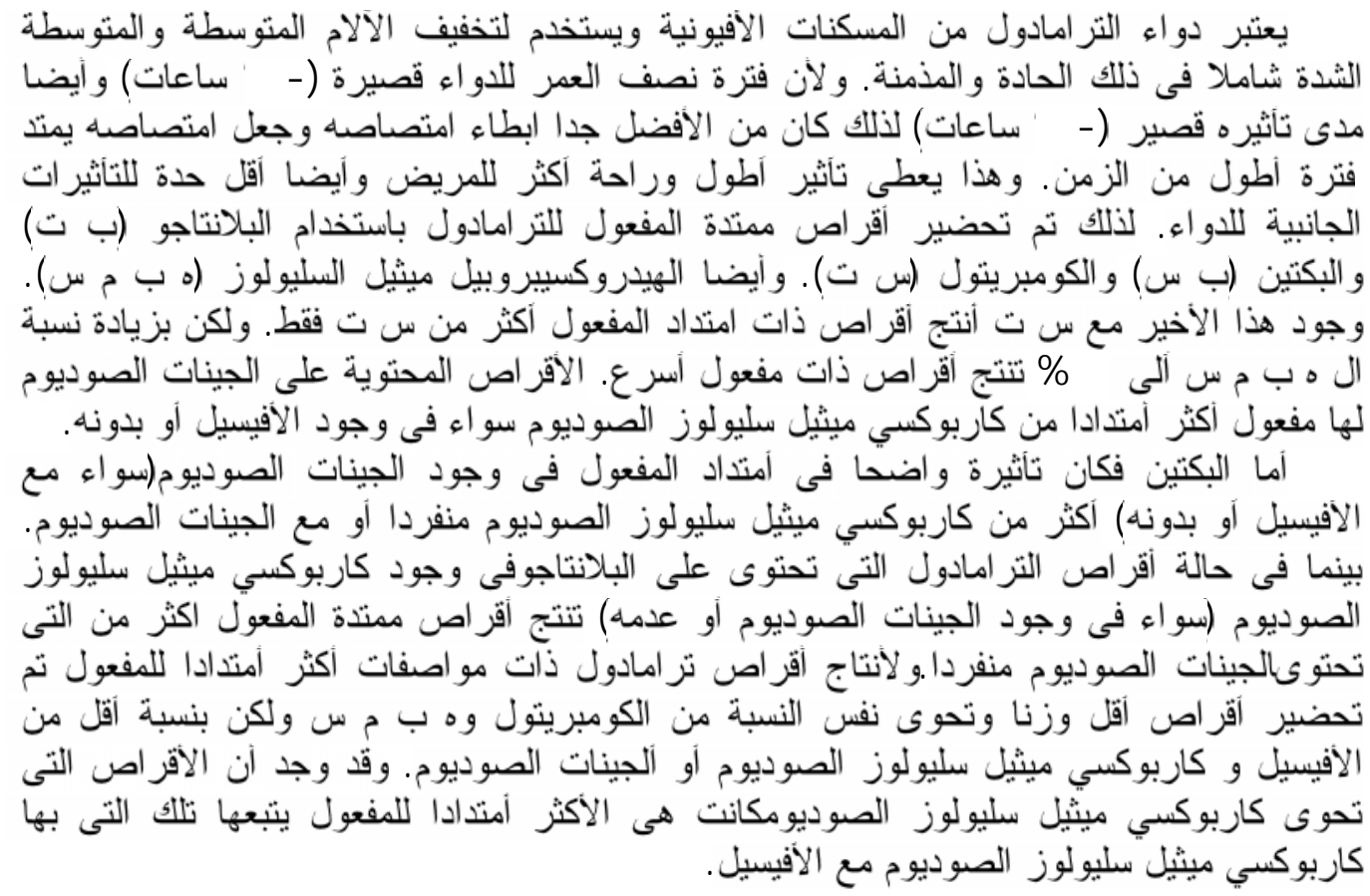

Tramadol is an opioid analgesic. It is indicated for the relief of moderate to moderately sever pain across the full range of acute and chronic pain syndromes. Due to its short half-life (5 to 7 hours) and its short duration of action ( 3 to 7 hours), it was highly desirable to slow the rate of absorption of tramadol and spread the absorption process over a longer interval, with increasing patient compliance and decreasing the risk and severity of adverse effects. Consequently, sustained release tramadol tablets were prepared utilizing the following materials: Compritol (CT), Plantago (PT), Pectin (PC), and HPMC. The inclusion of HPMC with CT, prolongs the release of tramadol more than CT alone. Also, by increasing HPMC concentration more sustaining effect could be obtained, but at $15 \%$ less sustaining effect was observed. The inclusion of NaAlg retards the release more than NaCMC, either with or without Avicel. PC showed pronounced sustaining effect with NaAlg alone (either with or without Avicel) compared to those containing NaCMC alone or with NaAlg. However, in case of tablets containing PT; the inclusion of NaCMC, either alone or in combination with NaAlg, retards the release of drug more than NaAlg alone. Aiming for more sustaining properties smaller tablets $(250 \mathrm{mg})$ containing the same proportions of CT and HPMC but lower \% of Avicel, NaCMC or NaAlg were prepared. Formula containing NaCMC alone showed the most sustaining effect (more than Tramal ${ }^{\circledR}$ ) followed by those including NaCMC and Avicel. 


\section{INTRODUCTION}

Water swellable matrices are widely used for the production of sustained-release tablets mainly due to their optimal performance and easy manufacturing. Several hydrophilic polymers have been investigated for this purpose. Hydroxypropylmethyl cellulose (HPMC) and sodium carboxymethyl cellulose $(\mathrm{NaCMC})$ are the most frequently polymers used for formulating sustained release matrices. ${ }^{1-8}$ Egg albumin (EA) also has been evaluated as a swellable material for the production of controlled release tablets for water-soluble drugs, e.g. aminophylline ${ }^{9}$ and, Ketorolac tromethamin, ${ }^{10}$ as well as, for water insoluble drug, e.g., carbamazepine (CZ). ${ }^{11}$ Plantago ovata seed husks have been utilized either alone ${ }^{12}$ or in combination with other commonly used hydrophilic polymers ${ }^{13}$ for this purpose. Also, Eudragit $\mathrm{RS}_{100}$ and gum tragacanth have been evaluated. ${ }^{14}$ The principal advantages of such polymers are that they can accommodate a high percentage of the drug and the drug release rate is generally independent of process variable. ${ }^{15}$ The mechanism of drug release from these hydrophilic systems have been studied. ${ }^{8-22}$

Tramadol $\mathrm{HCl}$ is a centrally acting nonnarcotic analgesic that is indicated for the treatment of moderate or moderately severe pain. ${ }^{23}$ Because of the comparatively short halflife of tramadol (5 to 7 hours) and its short duration of action (3 to 7 hours), immediaterelease formulations of oral tramadol are usually taken four times daily at doses of 50 to $100 \mathrm{mg}$. However, the maintenance of an optimum dosage regimen by frequent dose administration (e.g. 4 times daily) is always hampered by the inconvenience for the patient and the risk of noncompliance. Therefore, it was highly desirable to slow the rate of absorption of tramadol and spread the absorption process over a longer interval, thus providing a prolonged therapeutic activity with increasing the compliance and convenience for the patient and decreasing the risk and severity of adverse effects.

Thus, the aim of work in this investigation was to prepare sustained release matrix tablets of tramadol using glyceryl behenate (Compritol) (CT), Plantago (PT), Pectin (PC), and HPMC as swellable polymers. Also, to study the physical properties and the dissolution characteristics of the prepared tablets.

\section{EXPERIMENTAL}

\section{Materials}

Tramadol Hydrochloride, Batch No. 3891197, and Anhydrous lactose; from Al Hikma Comp, Amman, Jordan. Hydroxypropylmethyl cellulose HPMC (Acros Organics New Jersey-USA). Sodium carboxymethyl cellulose, NaCMC; C.B.H. LAB. Chemicals (Nottengham) UK. Microcrystalline cellulose Avicel PH101; Janssen-Chimica, Belgium. Sodium alginate, NaAlg, from Laboratory Rasayan (S.D. fine-Chem. LTD. Boisar). colloidal silica, Aerosil 200, Degussa, USA. Tramal $^{\circledR}$,Grünenthal, Gmbh, Germany, Lot 336B.

\section{Methods}

\section{Preparation of tablets}

Matrix tablets of Tramadol $\mathrm{HCl}$ were prepared using the formula shown in Tables 13. These formulas were chosen after many trials designed to obtain different degrees of sustaining effect. The ingredients were mixed in a cubic mixer (Erweka, Turbula System S27, Germany) for $10 \mathrm{~min}$, after passing through $335 \mu \mathrm{m}$ mesh screen. The mixture was compressed into $0.4 \mathrm{~g}$ flat tablets $(13 \mathrm{~mm}$ in diameter), as in Tables 1 and 2, or $0.25 \mathrm{~g}$ as in Table 3, using a Korsch, tableting machine (Korsch EK/O, Germany). Constant rate tableting machine adjusted to obtain tablets of hardness between 70 and 90 Newton in every case.

Table 1: Tablets containing different concentrations of compritol.

\begin{tabular}{||l|c|c|c|c||}
\hline Material (mg) & A1 & A2 & A3 & A4 \\
\hline Tramadol HCl & 100 & 100 & 100 & 100 \\
\hline Compritol & 37.5 & 30 & 22.5 & 15 \\
\hline Anhydrous lactose & -- & 7.5 & 15 & 22.5 \\
\hline Avicel & 107 & 107 & 107 & 107 \\
\hline Talc & 5 & 5 & 5 & 5 \\
\hline Aerosil & 0.5 & 0.5 & 0.5 & 0.5 \\
\hline
\end{tabular}


Table 2: Contents of each of the prepared tramadol tablet formulations.

\begin{tabular}{||l|c|c|c|c|c|c|c|c|c|c||}
\hline Material (mg) & Cont & $\mathrm{CT}^{(1)}$ & 1 & 2 & 3 & 4 & 5 & 6 & 7 & 8 \\
\hline Tramadol HCl & 100 & 100 & 100 & 100 & 100 & 100 & 100 & 100 & 100 & 100 \\
\hline Compritol & -- & 60 & 60 & 60 & 60 & 60 & 60 & 60 & 60 & 60 \\
\hline Additives ${ }^{(2)}$ & -- & -- & 48 & 48 & 48 & 48 & 48 & 48 & 60 & 80 \\
\hline Avicel & 291.2 & 231.2 & -- & -- & -- & 80 & 183.2 & 80 & 80 & 80 \\
\hline Na CMC & -- & -- & 91.6 & 183.2 & -- & 103.2 & -- & -- & 91.2 & 71.2 \\
\hline Na Alginate & -- & -- & 91.6 & -- & 183.2 & -- & -- & 103.2 & -- & -- \\
\hline Talc & 8 & 8 & 8 & 8 & 8 & 8 & 8 & 8 & 8 & 8 \\
\hline Aerosil & 0.8 & .08 & .08 & 0.8 & 0.8 & 0.8 & 0.8 & 0.8 & 0.8 & 0.8 \\
\hline Total Weight & 400 & 400 & 400 & 400 & 400 & 400 & 400 & 400 & 400 & 400 \\
\hline \hline
\end{tabular}

$\mathrm{CT}^{(1)}$ : Compritol, ${ }^{(2)}$ Additives: Pectin, PC, (E), Plantago, PT, (D), or HPMC, (C).

Table 3: Contents of tablet formulations containing HPMC with different additives.

\begin{tabular}{|l|c|c|c|c|c|c||}
\hline $\begin{array}{l}\text { Material Symbol } \\
(\mathrm{mg})\end{array}$ & E1 & E2 & E3 & E4 & E5 & E6 \\
\hline Tramadol & 100 & 100 & 100 & 100 & 100 & 100 \\
\hline Compritol & 37.5 & 37.5 & 37.5 & 37.5 & 37.5 & 37.5 \\
\hline HPMC & 37 & 37 & 37 & 37 & 37 & 37 \\
\hline Avicel & -- & 35 & -- & 35 & -- & 70 \\
\hline Na CMC & 35 & -- & -- & 35 & 70 & -- \\
\hline Na Alginate & 35 & 35 & 70 & -- & -- & -- \\
\hline Talc & 5 & 5 & 5 & 5 & 5 & 5 \\
\hline Aerosil & 0.5 & 0.5 & 0.5 & 0.5 & 0.5 & 0.5 \\
\hline Total weight & 250 & 250 & 250 & 250 & 250 & 250 \\
\hline
\end{tabular}

\section{Evaluation of tablets \\ Uniformity of weight}

Twenty tablets taken randomly were weighed individually and tested according to the USP/NF 1995 test (the deviation from the mean must not exceed $\pm 5 \%$ for $0.4 \mathrm{~g}$ tablets and $\pm 7.5 \%$ for $0.25 \mathrm{~g}$ ones). Also, the average weight, the standard deviation, and the coefficient of variation (C.V.\%) were calculated.

\section{Uniformity of diameter and thickness}

The diameter and thickness of twenty tablets were determined individually using
Erweka Hardness Tester $\mathrm{TBH}_{30}$, Germany. Also, the average and C.V. percent were calculated.

\section{Tensile strength}

The tensile strength $\left(\mathrm{T}_{\mathrm{s}}\right)$ was calculated from the equation:

$$
\mathrm{T}_{\mathrm{s}}=2 \mathrm{H} / \pi \mathrm{TD} \ldots .\left(\text { Newton } / \mathrm{cm}^{2}\right)
$$

Where: "T" is the thickness, " $\mathrm{D}$ " is the diameter, and " $\mathrm{H}$ " is the hardness (in Newton, $\mathrm{N}$ ) of the tablets (was determined using Erweka $\mathrm{TBH}_{30}$ hardness tester) and the average 
hardness of 10 tablets taken randomly and the C.V.\% can be also calculated.

\section{Friability}

The percentage weight loss was determined after rotation of twenty preweighed tablets for $4 \mathrm{~min}$. at $25 \mathrm{rpm}$. using Erweka Friabilator $\mathrm{TAR}_{20}$.

\section{Disintegration time}

The average of time required for the disintegration of 6 tablets was also determined using Pharma Test, (Italy) apparatus.

\section{Dissolution studies}

A USP/NF ${ }_{1995}$ Hanson dissolution apparatus with six baskets was employed for this purpose. One tablet was placed in each basket, rotating at $100 \mathrm{rpm}$ in $900 \mathrm{ml}$ of the dissolution medium $(0.1 \mathrm{~N} \mathrm{HCl}, \mathrm{pH} 1.2$, or phosphate buffer of $\mathrm{pH} 6.8)$ at $37^{\circ}$. The experiment was run for 6.5 hours. The acid medium was employed during the first three hours, and then it was replaced by the phosphate buffer medium for the next three and half hours. Filtered samples were withdrawn at suitable time intervals and replaced by equal volumes of dissolution medium kept at $37^{\circ}$. Samples were assayed spectrophotometrically, after appropriate dilution, at $270.7 \mathrm{~nm}$ for tramadol $\mathrm{HCl}$.

\section{RESULTS AND DISCUSSION}

Because of the comparatively short halflife of tramadol $\mathrm{HCl}$ (5 to 7 hours) and its short duration of action ( 3 to 7 hours), it was highly desirable to slow the rate of absorption of tramadol and spread the absorption process over a longer interval, thus providing a prolonged therapeutic activity with increasing the compliance and convenience for the patient and decreasing the risk and severity of adverse effects. Consequently, sustained release tramadol tablets were prepared utilizing the following materials: Compritol (CT), Plantago (PT), Pectin (PC), and HPMC.

Tables 4-7 represent the physical properties of the prepared tramadol matrix tablets. All the tested formulations show acceptable friability values (FV) according to the USP/NF ${ }_{1995}$ requirements (FV not exceeds $1 \%$ in all cases). The tensile strength $\left(\mathrm{T}_{\mathrm{s}}\right)$ values were found to be suitable for all the prepared tablets. All the prepared tablets successfully fulfill the requirements with respect to the uniformity of weight (the deviation not exceed $\pm 10 \%$ for all tablets). The uniformity of diameter was also acceptable for $\mathrm{USP} / \mathrm{NF}_{1995}$ requirements. The uniformity of thickness values was suitable. The disintegration time values (Table 4) revealed that; tramadol tablets (control formula) containing Avicel without sustaining vehicles showed very rapid disintegration time (less than 50 seconds), but those containing CT disintegrated through $30 \mathrm{~min}$. Whereas, the inclusion of the tested sustaining vehicles, in the same formula, mostly retard the disintegration time of tablets to more than one hour.

Compritol (CT) is mainly used as a lubricant for tablet preparation. It has water repellant capacity. In this investigation it was tested for producing sustained release Tramadol tablets. Preliminary study was performed to evaluate its inclusion alone (Table 1). The results obtained (Fig. 1) reveal that it is more effective at 12 and $15 \%$ concentrations. Pectin (PC) was tested for the production of tramadol sustained release tablets using the formulas shown in Table 2. PC show pronounced sustaining effect with $\mathrm{NaAlg}$ alone (either with or without Avicel) compared to those containing $\mathrm{NaCMC}$ or $\mathrm{NaCMC}$ with NaAlg (Figs. 2,3). Upon increasing the proportion of PC to 15 and $20 \%$ (Fig. 4), no marked increase could be detected.

Recently, Plantago ovata seed husks have been successfully used as hydrophilic swellable material for sustaining drug release. ${ }^{12,13}$ The inclusion of $\mathrm{NaCMC}$, either alone or in combination with NaAlg, (Figs. 5,6) retards the release of drug more than $\mathrm{NaAlg}$ alone (in contrast to PC formulations). However, in presence of Avicel, PT with NaCMC show very rapid release compared to Avicel alone or with NaAlg. This may also, be attributed to the strong disintegrating effect of such combination. This explanation may be confirmed by the results of the very rapid disintegration and dissolution obtained by increasing PT concentration with decreasing $\mathrm{NaCMC}$ (Fig. 7). 
Table 4: Physical properties of the prepared tramadol tablets containing compritol.

\begin{tabular}{|c|c|c|c|c|c|c|}
\hline Properties & $\begin{array}{l}\text { Uniformity } \\
\text { of } \\
\text { weight } \\
(\mathrm{g}) \\
\end{array}$ & $\begin{array}{l}\text { Uniformity } \\
\text { of } \\
\text { thickness } \\
(\mathrm{mm}) \\
\end{array}$ & $\begin{array}{l}\text { Uniformity } \\
\text { of } \\
\text { Diameter } \\
(\mathrm{mm}) \\
\end{array}$ & $\begin{array}{l}\text { Tensile } \\
\text { strength } \\
\left(\mathrm{N} / \mathrm{cm}^{2}\right)\end{array}$ & $\begin{array}{l}\text { Friability } \\
\text { value } \\
\text { (Loss \%) }\end{array}$ & $\begin{array}{c}\text { Disintegration } \\
\text { time } \\
\text { (minute) }\end{array}$ \\
\hline $\begin{array}{c}\text { Cont } \\
(\mathrm{TL}+\text { Avicel })\end{array}$ & $\begin{array}{c}0.4086 \\
(2.1044)\end{array}$ & $\begin{array}{c}2.8667 \\
(1.0070)\end{array}$ & $\begin{array}{l}13.00 \\
(0.0)\end{array}$ & $\begin{array}{c}119.88 \\
(6.3810)\end{array}$ & 0.389 & 0.79 \\
\hline $\begin{array}{c}\text { TL, Avicel + } \\
\text { CT }\end{array}$ & $\begin{array}{c}0.3936 \\
(1.1168)\end{array}$ & $\begin{array}{c}2.7333 \\
(1.0561)\end{array}$ & $\begin{array}{l}13.00 \\
(0.0)\end{array}$ & $\begin{array}{c}119.88 \\
(6.3810)\end{array}$ & 0.376 & 29.81 \\
\hline $\begin{array}{c}\mathrm{A} 1 \\
(15 \% \mathrm{CT}) \\
\end{array}$ & $\begin{array}{c}0.2586 \\
(1.8192) \\
\end{array}$ & $\begin{array}{l}4.55 \\
(0.0) \\
\end{array}$ & $\begin{array}{r}8.00 \\
(0.0) \\
\end{array}$ & $\begin{array}{c}151.58 \\
(5.4530) \\
\end{array}$ & 0.058 & 13.68 \\
\hline $\begin{array}{c}\mathrm{A} 2 \\
(12 \% \mathrm{CT})\end{array}$ & $\begin{array}{c}0.2671 \\
(2.1157)\end{array}$ & $\begin{array}{c}4.567 \\
(0.6321)\end{array}$ & $\begin{array}{l}8.00 \\
(0.0)\end{array}$ & $\begin{array}{l}140.56 \\
(13.93)\end{array}$ & 0.094 & 16.17 \\
\hline $\begin{array}{c}\mathrm{A} 3 \\
(9 \% \mathrm{CT})\end{array}$ & $\begin{array}{c}0.2581 \\
(4.3388))\end{array}$ & $\begin{array}{l}4.533 \\
(.6368)\end{array}$ & $\begin{array}{c}8.0167 \\
(0.3601)\end{array}$ & $\begin{array}{c}154.16 \\
(12.654)\end{array}$ & 0.058 & 14.26 \\
\hline $\begin{array}{c}\mathrm{A} 4 \\
(6 \% \mathrm{CT})\end{array}$ & $\begin{array}{c}0.2629 \\
(1.2578)\end{array}$ & $\begin{array}{c}4.6167 \\
(0.6253)\end{array}$ & $\begin{array}{l}8.0167 \\
(.3601)\end{array}$ & $\begin{array}{c}131.87 \\
(8.4866)\end{array}$ & 0.111 & 14.82 \\
\hline
\end{tabular}

Table 5: Physical properties of the prepared tramadol tablets containing pectin.

\begin{tabular}{|c|c|c|c|c|c|c|}
\hline Symbol Properties & $\begin{array}{l}\text { Uniformity } \\
\text { of } \\
\text { weight } \\
(\mathrm{g})\end{array}$ & $\begin{array}{l}\text { Uniformity } \\
\text { of } \\
\text { thickness } \\
(\mathrm{mm})\end{array}$ & $\begin{array}{l}\text { Uniformity } \\
\text { of } \\
\text { Diameter } \\
(\mathrm{mm})\end{array}$ & $\begin{array}{l}\text { Tensile } \\
\text { strength } \\
\left(\mathrm{N} / \mathrm{cm}^{2}\right)\end{array}$ & $\begin{array}{l}\text { Friability } \\
\text { Value } \\
\text { (Loss \%) }\end{array}$ & $\begin{array}{c}\text { Disintegration } \\
\text { time } \\
\text { (minute) }\end{array}$ \\
\hline $\begin{array}{c}\mathrm{B} 1 \\
(\mathrm{PC}+\mathrm{NaCMC}+\mathrm{Na} \cdot \mathrm{Alg})\end{array}$ & $\begin{array}{c}0.4103 \\
(0.9414)\end{array}$ & $\begin{array}{l}2.4833 \\
(1.1625)\end{array}$ & $\begin{array}{l}13.00 \\
(0.0)\end{array}$ & $\begin{array}{c}147.24 \\
(4.7034)\end{array}$ & 0.766 & $>60$ \\
\hline $\begin{array}{c}\mathrm{B} 2 \\
(\mathrm{PC}+\mathrm{NaCMC})\end{array}$ & $\begin{array}{c}0.4128 \\
(3.8070)\end{array}$ & $\begin{array}{c}2.4167 \\
(1.1703)\end{array}$ & $\begin{array}{l}13.00 \\
(0.0)\end{array}$ & $\begin{array}{c}167.51 \\
(6.8785)\end{array}$ & 0.747 & 45.68 \\
\hline $\begin{array}{c}\mathrm{B} 3 \\
(\mathrm{PC}+\mathrm{NaAlg} .)\end{array}$ & $\begin{array}{c}0.4030 \\
(4.3442) \\
\end{array}$ & $\begin{array}{c}2.4333 \\
(1.1863) \\
\end{array}$ & $\begin{array}{l}13.00 \\
(0.0)\end{array}$ & $\begin{array}{c}150.27 \\
(4.3052) \\
\end{array}$ & 0.870 & $>60$ \\
\hline $\begin{array}{c}\mathrm{B} 4 \\
(12 \% \mathrm{PC}) \\
(\text { Avicel }+\mathrm{NaCMC})\end{array}$ & $\begin{array}{c}0.4003 \\
(1.1427)\end{array}$ & $\begin{array}{c}2.4833 \\
(1.1625)\end{array}$ & $\begin{array}{l}13.00 \\
(0.0)\end{array}$ & $\begin{array}{c}169.59 \\
(3.0765)\end{array}$ & 0.713 & 37.19 \\
\hline $\begin{array}{c}\text { B5 } \\
(\mathrm{PC}+\text { Avicel }) \\
\end{array}$ & $\begin{array}{c}0.3885 \\
(1.7895) \\
\end{array}$ & $\begin{array}{c}2.4333 \\
(1.1863) \\
\end{array}$ & $\begin{array}{c}13.00 \\
(0.0) \\
\end{array}$ & $\begin{array}{c}169.05 \\
(3.1497) \\
\end{array}$ & 0.135 & 33.51 \\
\hline $\begin{array}{c}\mathrm{B} 6 \\
(\mathrm{PC}+\text { Avicel }+\mathrm{NaAlg})\end{array}$ & $\begin{array}{c}0.4185 \\
(0.4139) \\
\end{array}$ & $\begin{array}{c}2.4167 \\
(1.1703) \\
\end{array}$ & $\begin{array}{l}13.00 \\
(0.0)\end{array}$ & $\begin{array}{c}148.60 \\
(3.4317) \\
\end{array}$ & 0.645 & $>60$ \\
\hline $\begin{array}{c}\mathrm{B} 7 \\
(15 \% \mathrm{PC}) \\
(\text { Avicel + NaCMC }) \\
\end{array}$ & $\begin{array}{c}0.4091 \\
(3.5416)\end{array}$ & $\begin{array}{c}2.4500 \\
(0.0)\end{array}$ & $\begin{array}{l}13.00 \\
(0.0)\end{array}$ & $\begin{array}{c}163.90 \\
(5.5885)\end{array}$ & 0.280 & $>60$ \\
\hline $\begin{array}{c}\mathrm{B} 8 \\
(20 \% \mathrm{PC}) \\
(\text { Avicel + NaCMC ) } \\
\end{array}$ & $\begin{array}{c}0.4065 \\
(2.8065)\end{array}$ & $\begin{array}{c}2.3833 \\
(1.2112)\end{array}$ & $\begin{array}{l}13.00 \\
(0.0)\end{array}$ & $\begin{array}{l}165.06 \\
(6.2645)\end{array}$ & 0.434 & $>60$ \\
\hline
\end{tabular}

Values between parentheses are the coefficient of variation (C.V)\% 
Table 6A: Physical properties of the prepared tramadol tablets containing plantago.

\begin{tabular}{|c|c|c|c|c|c|c|}
\hline $\mathrm{P}_{\text {Symbol }}^{\text {Formula }}$ & $\begin{array}{l}\text { Uniformity } \\
\text { of } \\
\text { weight } \\
\text { (g) }\end{array}$ & $\begin{array}{l}\begin{array}{l}\text { Uniformity } \\
\text { of } \\
\text { thickness } \\
(\mathrm{mm})\end{array} \\
\end{array}$ & $\begin{array}{l}\begin{array}{l}\text { Uniformity } \\
\text { of } \\
\text { Diameter } \\
(\mathrm{mm})\end{array} \\
\end{array}$ & $\begin{array}{l}\text { Tensile } \\
\text { strength } \\
\left(\mathrm{N} / \mathrm{cm}^{2}\right)\end{array}$ & $\begin{array}{l}\text { Friability } \\
\text { Value } \\
\text { (Loss \%) }\end{array}$ & $\begin{array}{c}\text { Disintegration } \\
\text { time } \\
\text { (minute) }\end{array}$ \\
\hline $\begin{array}{c}\mathrm{C} 1 \\
(\mathrm{PT}+\mathrm{NaCMC}+ \\
\mathrm{Na} . \mathrm{Alg})\end{array}$ & $\begin{array}{c}0.4003 \\
(2.3823)\end{array}$ & $\begin{array}{c}2.5167 \\
(1.1471)\end{array}$ & $\begin{array}{l}13.00 \\
(0.0)\end{array}$ & $\begin{array}{c}153.72 \\
(3.7975)\end{array}$ & 0.825 & $>60$ \\
\hline $\begin{array}{c}\mathrm{C} 2 \\
(\mathrm{PT}+\mathrm{NaCMC})\end{array}$ & $\begin{array}{c}0.3880 \\
(1.8041)\end{array}$ & $\begin{array}{c}2.4667 \\
(1.1703)\end{array}$ & $\begin{array}{l}13.00 \\
(0.0)\end{array}$ & $\begin{array}{l}150.88 \\
(6.0297)\end{array}$ & 0.5059 & $>60$ \\
\hline $\begin{array}{c}\mathrm{C} 3 \\
(\mathrm{PT}+\mathrm{Na}-\text { Alginate })\end{array}$ & $\begin{array}{c}0.4078 \\
(2.2568)\end{array}$ & $\begin{array}{c}2.5167 \\
(1.1471)\end{array}$ & $\begin{array}{c}13.00 \\
(0.0)\end{array}$ & $\begin{array}{c}147.23 \\
(6.6518)\end{array}$ & 0.376 & $>60$ \\
\hline $\begin{array}{c}\mathrm{C} 4 \\
(12 \% \mathrm{PT}) \\
\text { (Avicel + Na-CMC ) }\end{array}$ & $\begin{array}{c}0.3886 \\
(1.6336)\end{array}$ & $\begin{array}{c}2.4667 \\
(1.1703)\end{array}$ & $\begin{array}{l}13.00 \\
(0.0)\end{array}$ & $\begin{array}{c}148.23 \\
(7.3762)\end{array}$ & 0.659 & 5.22 \\
\hline $\begin{array}{c}\mathrm{C} 5 \\
(\mathrm{PT}+\text { Avicel }) \\
\end{array}$ & $\begin{array}{c}0.4067 \\
(2.2252) \\
\end{array}$ & $\begin{array}{c}2.4333 \\
(1.1625) \\
\end{array}$ & $\begin{array}{c}13.00 \\
(0.0)\end{array}$ & $\begin{array}{c}155.79 \\
(6.5774) \\
\end{array}$ & 0.407 & $>60$ \\
\hline $\begin{array}{c}\mathrm{C} 6 \\
(\mathrm{PT}+\text { Avicel }+\mathrm{NaAlg}) \\
\end{array}$ & $\begin{array}{c}0.3949 \\
(3.2282) \\
\end{array}$ & $\begin{array}{c}2.4833 \\
(1.1625) \\
\end{array}$ & $\begin{array}{l}13.00 \\
(0.0)\end{array}$ & $\begin{array}{l}154.47 \\
(2.9842) \\
\end{array}$ & 0.736 & $>60$ \\
\hline $\begin{array}{c}\mathrm{C} 7 \\
(15 \% \mathrm{PT}) \\
(\text { Avicel + NaCMC ) }\end{array}$ & $\begin{array}{c}0.3965 \\
(3.4536)\end{array}$ & $\begin{array}{c}2.4667 \\
(1.1703)\end{array}$ & $\begin{array}{l}13.00 \\
(0.0)\end{array}$ & $\begin{array}{c}163.45 \\
(4.2654)\end{array}$ & 0.848 & 5.81 \\
\hline $\begin{array}{c}\mathrm{C} 8 \\
(20 \% \mathrm{PT}) \\
(\text { Avicel + Na-CMC })\end{array}$ & $\begin{array}{l}0.3925 \\
(1.676)\end{array}$ & $\begin{array}{c}2.4333 \\
(1.1863)\end{array}$ & $\begin{array}{l}13.00 \\
(0.0)\end{array}$ & $\begin{array}{c}166.37 \\
(6.0886)\end{array}$ & 0.627 & $>60$ \\
\hline
\end{tabular}

Values between parentheses are the coefficient of variation (C.V)\%

Table 6B: Physical properties of the prepared tramadol tablets containing HPMC.

\begin{tabular}{|c|c|c|c|c|c|c|}
\hline $\mathrm{P}_{\text {Symbol }}^{\text {Formula }}$ & $\begin{array}{l}\text { Uniformity } \\
\text { of } \\
\text { weight } \\
(\mathrm{g})\end{array}$ & $\begin{array}{l}\text { Uniformity } \\
\text { of } \\
\text { thickness } \\
(\mathrm{mm})\end{array}$ & $\begin{array}{l}\text { Uniformity } \\
\text { of } \\
\text { Diameter } \\
(\mathrm{mm})\end{array}$ & $\begin{array}{l}\text { Tensile } \\
\text { strength } \\
\left(\mathrm{N} / \mathrm{cm}^{2}\right)\end{array}$ & $\begin{array}{l}\text { Friability } \\
\text { Value } \\
\text { (Loss \%) }\end{array}$ & $\begin{array}{c}\text { Disintegration } \\
\text { time } \\
\text { (minute) }\end{array}$ \\
\hline $\begin{array}{c}\mathrm{D} 1 \\
(\mathrm{HPMC}+\mathrm{Na}-\mathrm{CMC}+ \\
\mathrm{Na}-\mathrm{Alg}) \\
\end{array}$ & $\begin{array}{c}0.4034 \\
(2.1994)\end{array}$ & $\begin{array}{c}2.4667 \\
(1.1703)\end{array}$ & $\begin{array}{l}13.00 \\
(0.0)\end{array}$ & $\begin{array}{c}167.42 \\
(3.6226)\end{array}$ & 0.306 & $>60$ \\
\hline $\begin{array}{c}\mathrm{D} 2 \\
(\mathrm{HPMC}+\mathrm{Na}-\mathrm{CMC})\end{array}$ & $\begin{array}{c}0.4022 \\
(2.5130)\end{array}$ & $\begin{array}{c}2.4333 \\
(1.1863)\end{array}$ & $\begin{array}{l}13.00 \\
(0.0)\end{array}$ & $\begin{array}{c}174.42 \\
(2.4019)\end{array}$ & 0.264 & $>60$ \\
\hline $\begin{array}{c}\mathrm{D} 3 \\
(\text { HPMC }+ \text { Na-Alginate }) \\
\end{array}$ & $\begin{array}{c}0.4130 \\
(2.7249) \\
\end{array}$ & $\begin{array}{c}2.4833 \\
(1.1625) \\
\end{array}$ & $\begin{array}{l}13.00 \\
(0.0) \\
\end{array}$ & $\begin{array}{c}146.59 \\
(5.4369) \\
\end{array}$ & 0.894 & $>60$ \\
\hline $\begin{array}{c}\mathrm{D} 4 \\
(12 \% \text { HPMC }) \\
(\text { Avicel + Na-CMC })\end{array}$ & $\begin{array}{c}0.4114 \\
(2.7249)\end{array}$ & $\begin{array}{c}2.5167 \\
(1.1471)\end{array}$ & $\begin{array}{r}13.00 \\
(0.0)\end{array}$ & $\begin{array}{c}173.18 \\
(4.4944)\end{array}$ & 0.429 & 38.09 \\
\hline $\begin{array}{c}\text { D5 } \\
\text { (HPMC + Avicel) } \\
\end{array}$ & $\begin{array}{c}0.4046 \\
(2.9630) \\
\end{array}$ & $\begin{array}{c}2.333 \\
(1.1395) \\
\end{array}$ & $\begin{array}{l}13.00 \\
(0.0) \\
\end{array}$ & $\begin{array}{c}159.80 \\
(3.0443) \\
\end{array}$ & 0.232 & $>60$ \\
\hline $\begin{array}{c}\text { D6 } \\
\text { (HPMC + Avicel + } \\
\text { Na-Alg.) }\end{array}$ & $\begin{array}{c}0.3984 \\
(1.4853)\end{array}$ & $\begin{array}{l}2.41667 \\
(1.1945)\end{array}$ & $\begin{array}{r}13.00 \\
(0.0)\end{array}$ & $\begin{array}{c}153.33 \\
(5.5022)\end{array}$ & 0.608 & $>60$ \\
\hline $\begin{array}{c}\mathrm{D} 7 \\
(15 \% \text { HPMC }) \\
\text { (Avicel + Na-CMC) }\end{array}$ & $\begin{array}{c}0.4017 \\
(2.6339)\end{array}$ & $\begin{array}{c}2.4333 \\
(1.1863)\end{array}$ & $\begin{array}{c}13.00 \\
(0.0)\end{array}$ & $\begin{array}{c}175.76 \\
(5.1633)\end{array}$ & 0.439 & 31.99 \\
\hline $\begin{array}{c}\text { D8 } \\
(20 \% \text { HPMC ) } \\
\text { (Avicel + Na-Alg.) }\end{array}$ & $\begin{array}{c}0.3912 \\
(2.0760)\end{array}$ & $\begin{array}{c}2.4000 \\
(0.0)\end{array}$ & $\begin{array}{r}13.00 \\
(0.0)\end{array}$ & $\begin{array}{c}172.76 \\
(1.3638)\end{array}$ & 0.156 & 33.86 \\
\hline
\end{tabular}

Values between parentheses are the coefficient of variation (C.V)\% 
Table 7: Physical properties of the prepared Tramadol tablets containing HPMC with different additives $(250 \mathrm{mg})$.

\begin{tabular}{|c|c|c|c|c|c|c|}
\hline Symbol & $\begin{array}{l}\text { Uniformity } \\
\text { of } \\
\text { weight } \\
\text { (g) }\end{array}$ & $\begin{array}{l}\text { Uniformity } \\
\text { of } \\
\text { thickness } \\
(\mathrm{mm})\end{array}$ & $\begin{array}{l}\text { Uniformity } \\
\text { of } \\
\text { Diameter } \\
(\mathrm{mm})\end{array}$ & $\begin{array}{l}\text { Tensile } \\
\text { strength } \\
\left(\mathrm{N} / \mathrm{cm}^{2}\right)\end{array}$ & $\begin{array}{c}\text { Friability } \\
\text { Value } \\
\text { (Loss \%) }\end{array}$ & $\begin{array}{l}\text { Disintegration } \\
\text { time } \\
\text { (minute) }\end{array}$ \\
\hline $\begin{array}{c}\mathrm{E} 1 \\
(\mathrm{HPMC}+\mathrm{Na}-\mathrm{CMC}+ \\
\mathrm{Na}-\mathrm{Alg})\end{array}$ & $\begin{array}{c}0.2640 \\
(1.6940)\end{array}$ & $\begin{array}{c}4.9833 \\
(0.5793)\end{array}$ & $\begin{array}{c}8.00 \\
(0.00)\end{array}$ & $\begin{array}{c}128.28 \\
(3.8030)\end{array}$ & 0.335 & $>60$ \\
\hline $\begin{array}{c}\text { E2 } \\
\text { (HPMC + Avicel + } \\
\text { Na-Alg.) }\end{array}$ & $\begin{array}{c}0.2673 \\
(4.4867)\end{array}$ & $\begin{array}{l}4.8667 \\
(2.3727)\end{array}$ & $\begin{array}{c}8.00 \\
(0.00)\end{array}$ & $\begin{array}{c}125.36 \\
(6.6934)\end{array}$ & 0.0757 & $>60$ \\
\hline $\begin{array}{c}\text { E3 } \\
\text { (HPMC + Na-Alg.) }\end{array}$ & $\begin{array}{c}0.2616 \\
(1.7642) \\
\end{array}$ & $\begin{array}{l}4.9833 \\
(0.5793) \\
\end{array}$ & $\begin{array}{r}8.00 \\
(0.00) \\
\end{array}$ & $\begin{array}{c}137.33 \\
(2.0458) \\
\end{array}$ & 0.220 & $>60$ \\
\hline $\begin{array}{c}\mathrm{E} 4 \\
(\mathrm{HPMC}+\text { Avicel } \\
+\mathrm{Na}-\mathrm{CMC})\end{array}$ & $\begin{array}{c}0.2518 \\
(2.4532)\end{array}$ & $\begin{array}{c}4.5333 \\
(0.6368)\end{array}$ & $\begin{array}{l}8.0167 \\
(0.3601\end{array}$ & $\begin{array}{c}130.80 \\
(2.0458)\end{array}$ & 0.079 & $>60$ \\
\hline $\begin{array}{c}\text { E5 } \\
(\mathrm{HPMC}+\mathrm{Na}-\mathrm{CMC})\end{array}$ & $\begin{array}{c}0.2550 \\
(1.9738)\end{array}$ & $\begin{array}{c}4.7333 \\
(1.2198)\end{array}$ & $\begin{array}{c}8.00 \\
(0.00)\end{array}$ & $\begin{array}{c}124.41 \\
(4.6812)\end{array}$ & 0.156 & $>60$ \\
\hline $\begin{array}{c}\text { E6 } \\
\text { (HPMC + Avicel) }\end{array}$ & $\begin{array}{c}0.2433 \\
(2.2696) \\
\end{array}$ & $\begin{array}{l}4.5167 \\
(0.6391) \\
\end{array}$ & $\begin{array}{c}8.00 \\
(0.00) \\
\end{array}$ & $\begin{array}{c}140.95 \\
(5.7282) \\
\end{array}$ & 0.0646 & 25.67 \\
\hline Tramal & $\begin{array}{c}0.3293 \\
(1.1496)\end{array}$ & $\begin{array}{c}5.05 \\
(0.00)\end{array}$ & $\begin{array}{l}10.1167 \\
(0.2853)\end{array}$ & $\begin{array}{c}120.04 \\
(5.3269)\end{array}$ & 0.091 & $>60$ \\
\hline
\end{tabular}

Values between parentheses are the coefficient of variation (C.V)\%

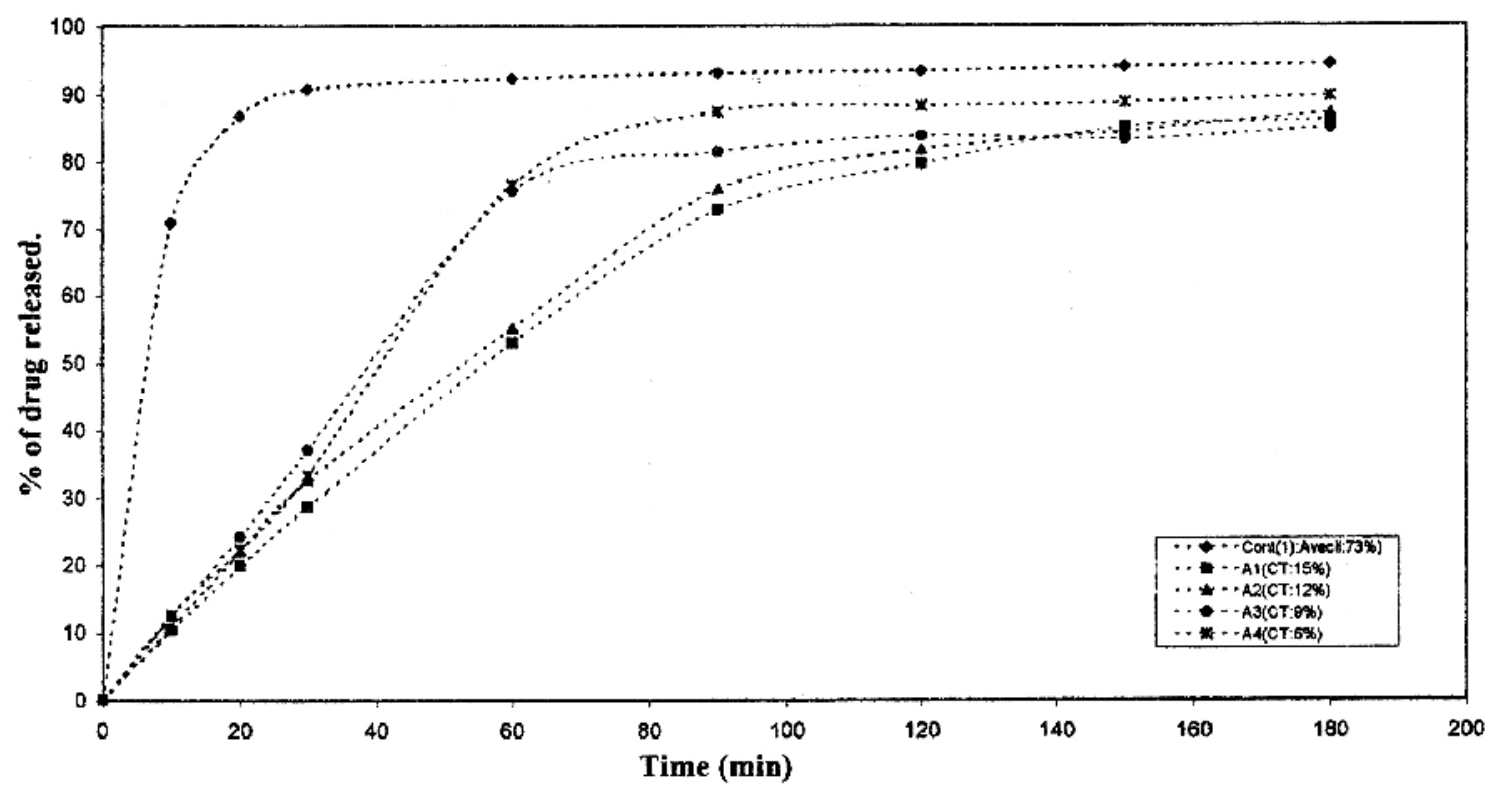

Fig. 1: Release profiles of tramadol from tablets containing different commpritol concentrations in acid medium ( $\mathrm{pH} 1.2)$. 


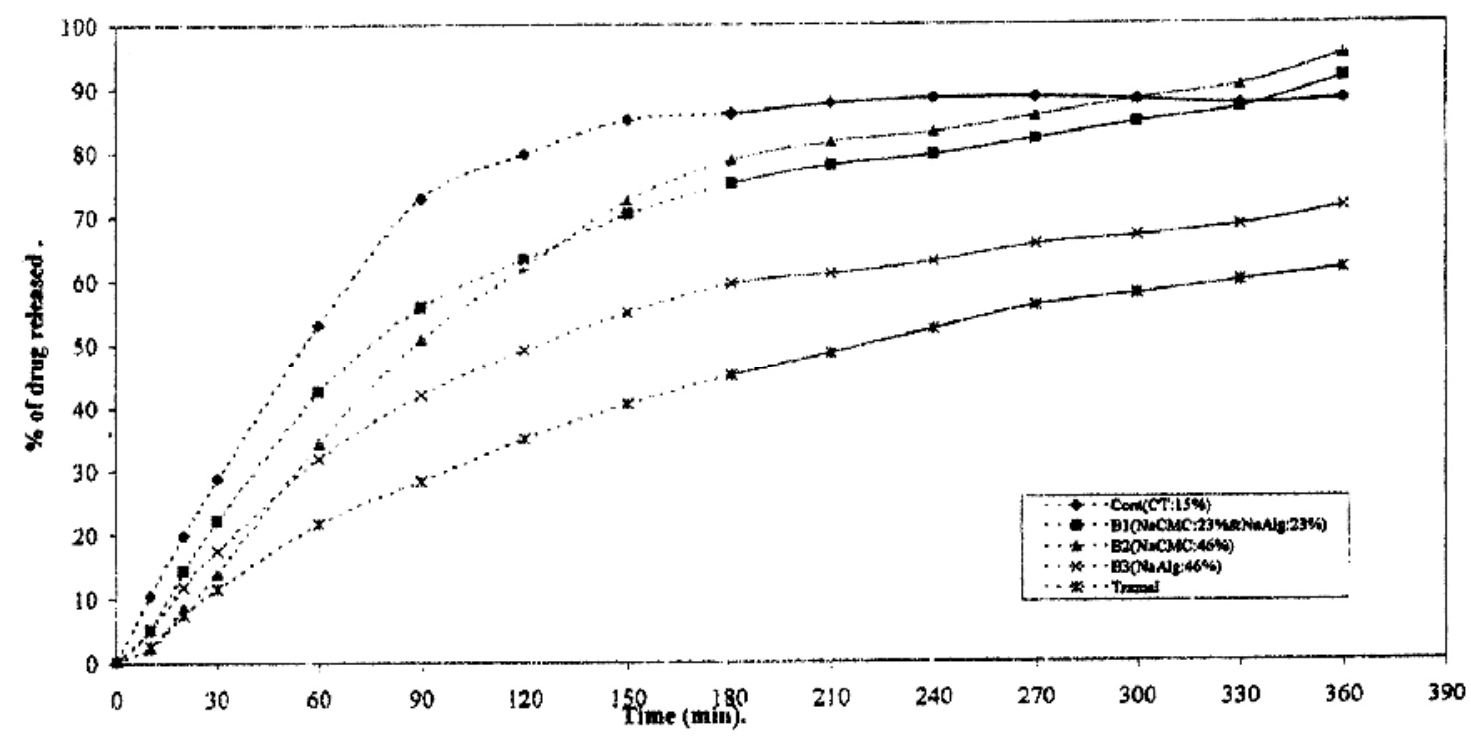

Fig. 2: Release profiles of tramadol from tablets containing compritol \& pectin with different proportions of NaCMC and NaAlg in acid, $\mathrm{pH} 1,2$ (dotted line) then in phosphate buffer, $\mathrm{pH}$ 6.8 (attached line) medium.

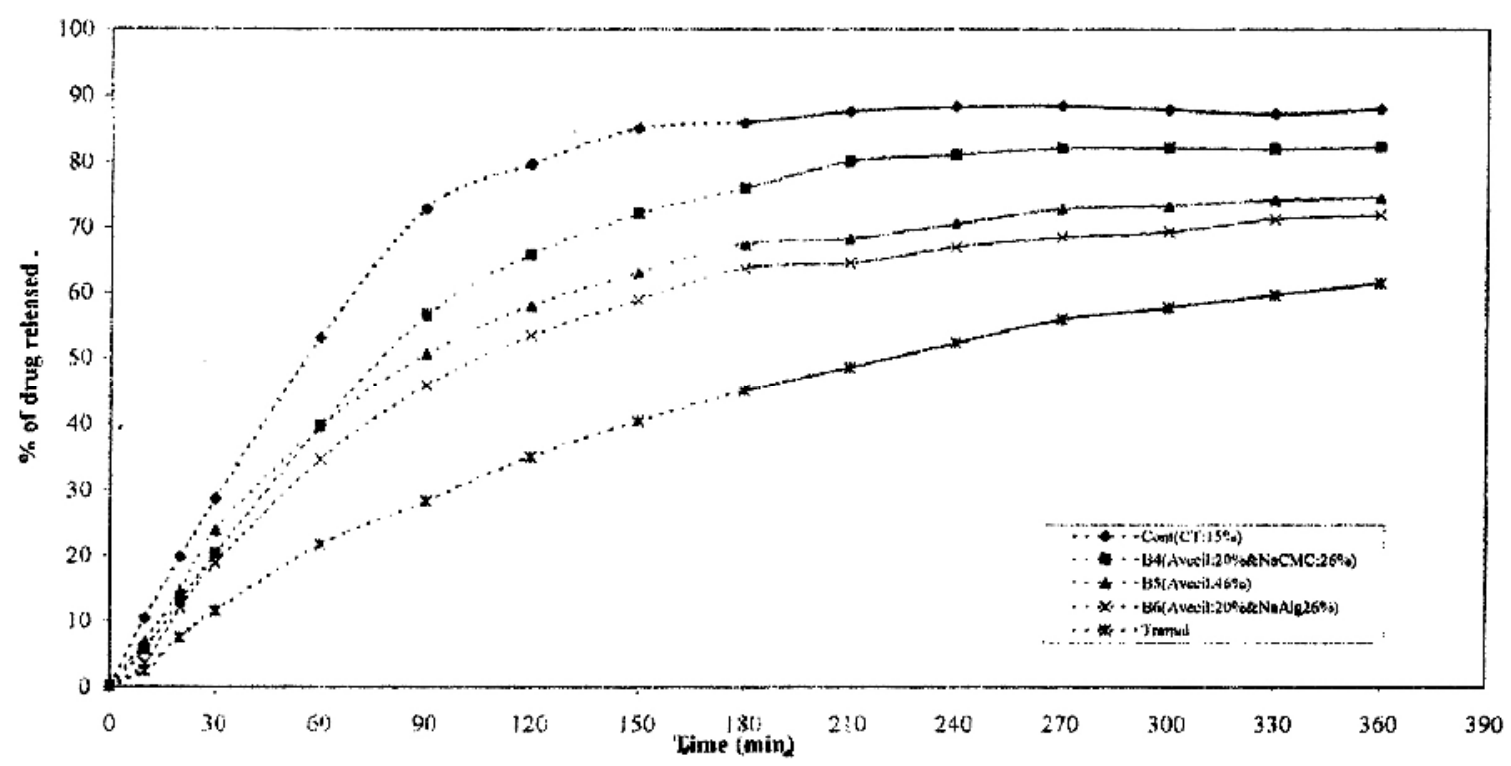

Fig. 3: Release profiles of tramadol from tablets containing compritol \& pectin with different proportions of Avicel, NaCMC and NaAlg in acid, $\mathrm{pH} 1,2$ (dotted line) then in phosphate buffer, pH 6.8 (attached line) medium. 


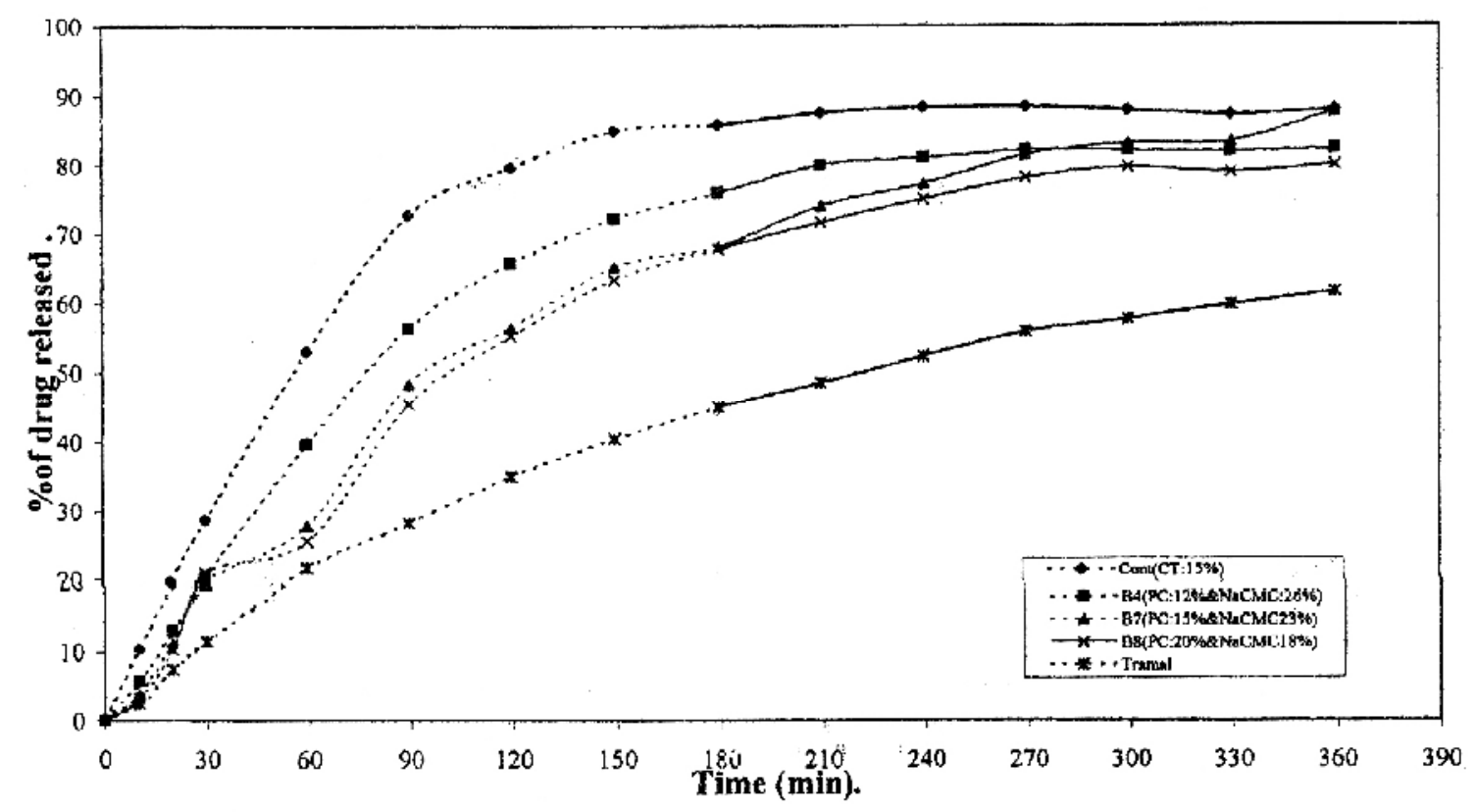

Fig. 4: Effect of increasing pectin proportions (with decreasing NaCMC) on the release of tramadol from the prepared tablets in acid, $\mathrm{pH} 1.2$ (dotted line) then in phosphate buffer, $\mathrm{pH} 6.8$ (attached line) medium.

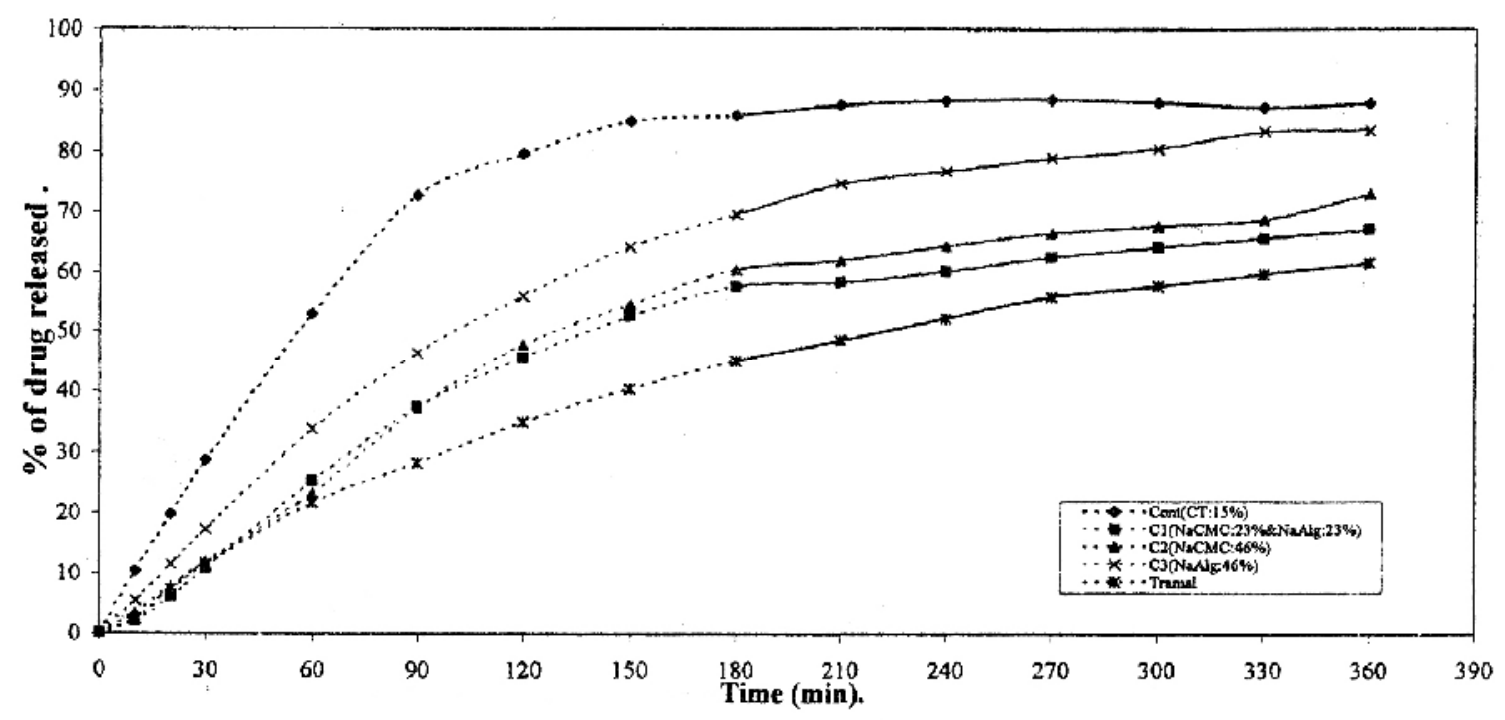

Fig. 5: Release profiles of tramadol from tablets containing compritol \& plantago with different proportions of NaCMC and NaAlg in acid, $\mathrm{pH} 1,2$ (dotted line) then in phosphate buffer, $\mathrm{pH}$ 6.8 (attached line) medium. 


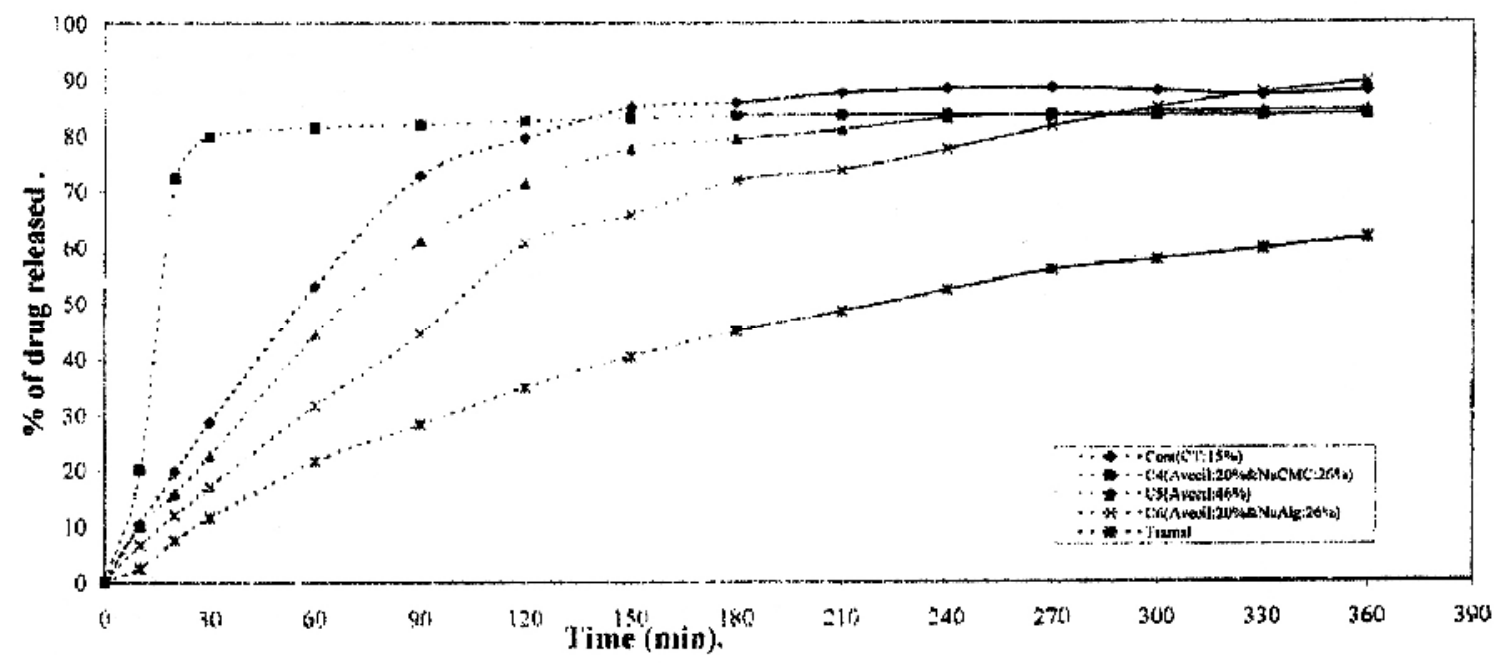

Fig. 6: Release profiles of tramadol from tablets containing compritol \& plantago with different proportions of Avicel, NaCMC and NaAlg in acid, $\mathrm{pH}$ 1,2 (dotted line) then in phosphate buffer, pH 6.8 (attached line) medium.

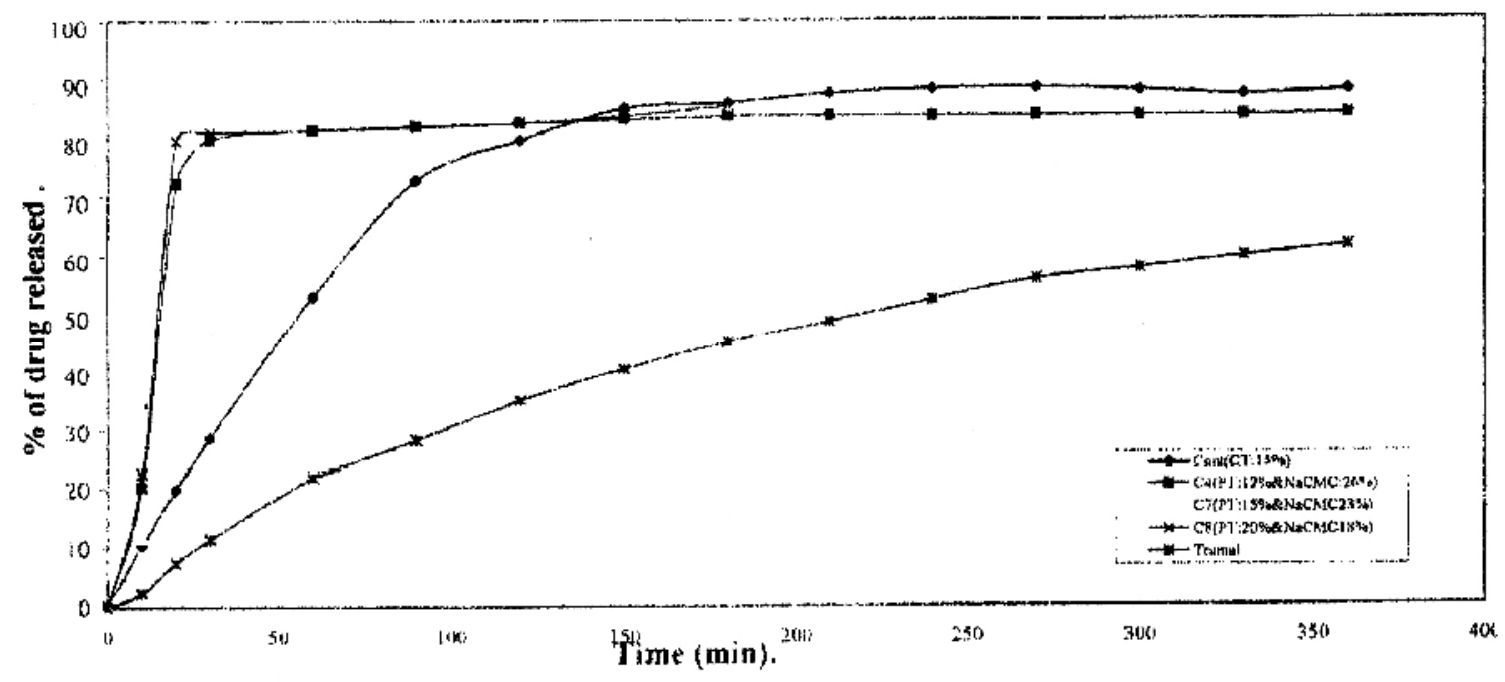

Fig. 7: Effect of increasing plantago proportions (with decreasing $\mathrm{NaCMC}$ ) on the release of tramadol from the prepared tablets in acid, $\mathrm{pH} 1.2$ (dotted line) then in phosphate buffer, $\mathrm{pH} 6.8$ (attached line) medium.

Furthermore, HPMC, the most currently used swellable polymer, were included with CT for preparing tramadol sustained release tablets (Table 3 and Figs. 8,9). Generally, this combination prolongs the release of tramadol more than CT alone. Also, by increasing HPMC concentration more sustaining effect could be obtained, but at $15 \%$ less sustaining is observed (Fig. 10). This may be attributed to the disintegrating effect of HPMC at this concentration. Figs. 12,13 revealed that the presence of NaAlg retard the release more than $\mathrm{NaCMC}$, either with or without Avicel. Also, the effect of increasing HPMC (with 
decreasing NaCMC) was studied (Fig. 10). Less sustaining effect could be observed upon increasing HPMC concentration, which confirms the above results (i.e. the increasing of disintegration time at $15 \%$ ). These results are Similar to those of PC.

A comparative study between the three tested sustaining materials (PC, PT and HPMC) revealed that PT show the most sustaining effect when included with $\mathrm{NaCMC}$ either alone (Fig. 11) or with NaAlg (Fig. 12), followed by HPMC then PC. However, the later two materials show better sustaining properties with NaAlg alone (Fig. 13) than with NaCMC (Fig. 14). On the other hand, the presence of Avicel, which is added to the formula as a direct compression vehicle, generally results in more rapid release, in most formulations, and this may be expected due to its known disintegrating effect. Thus, smaller tablets (250 $\mathrm{mg}$ ) containing the same proportions of CT and HPMC but lower \% of Avicel, NaCMC or NaAlg (Table 3 and Figs. 15,16) were prepared aiming for more sustaining properties. The results obtained revealed that; formula containing NaCMC alone show the most sustaining effect (more than Tramal $^{\circledR}$ ) followed by those including $\mathrm{NaCMC}$ and Avicel.

Generally, it could be observed that the release of tramadol $\mathrm{HCl}$ from all formulations in acid medium $(0.1 \mathrm{~N} \mathrm{HCl}, \mathrm{pH} 1.2)$ was pronouncedly more rapid than in phosphate buffer ( $\mathrm{pH}$ 6.8). This may be explained by the higher solubility of $\mathrm{HCl}$ salt of tramadol in acid medium, while in phosphate buffer ( $\mathrm{pH}$ 6.8) medium, the sodium ions react with the acid leaving the basic tramadol which is insoluble in water.

Upon studying the release kinetics utilizing Korsmeyer's equation:

$$
\log \mathrm{Q}=\log \mathrm{K}-\mathrm{n} \log \mathrm{t}
$$

Where; $\mathrm{Q}$ is the amount of drug released at time $\mathrm{t}, \mathrm{n}$ and $\mathrm{k}$ is the exponent and the kinetic constant of drug release, respectively.

The results obtained, which are presented in Tables 8 and 9, revealed that " $n$ " values are nearly one for all the tested excipients either in acid or phosphate buffer medium indicating the recommended zero-order release kinetics. This means that constant dissolution rate could be detected all over the releasing time.

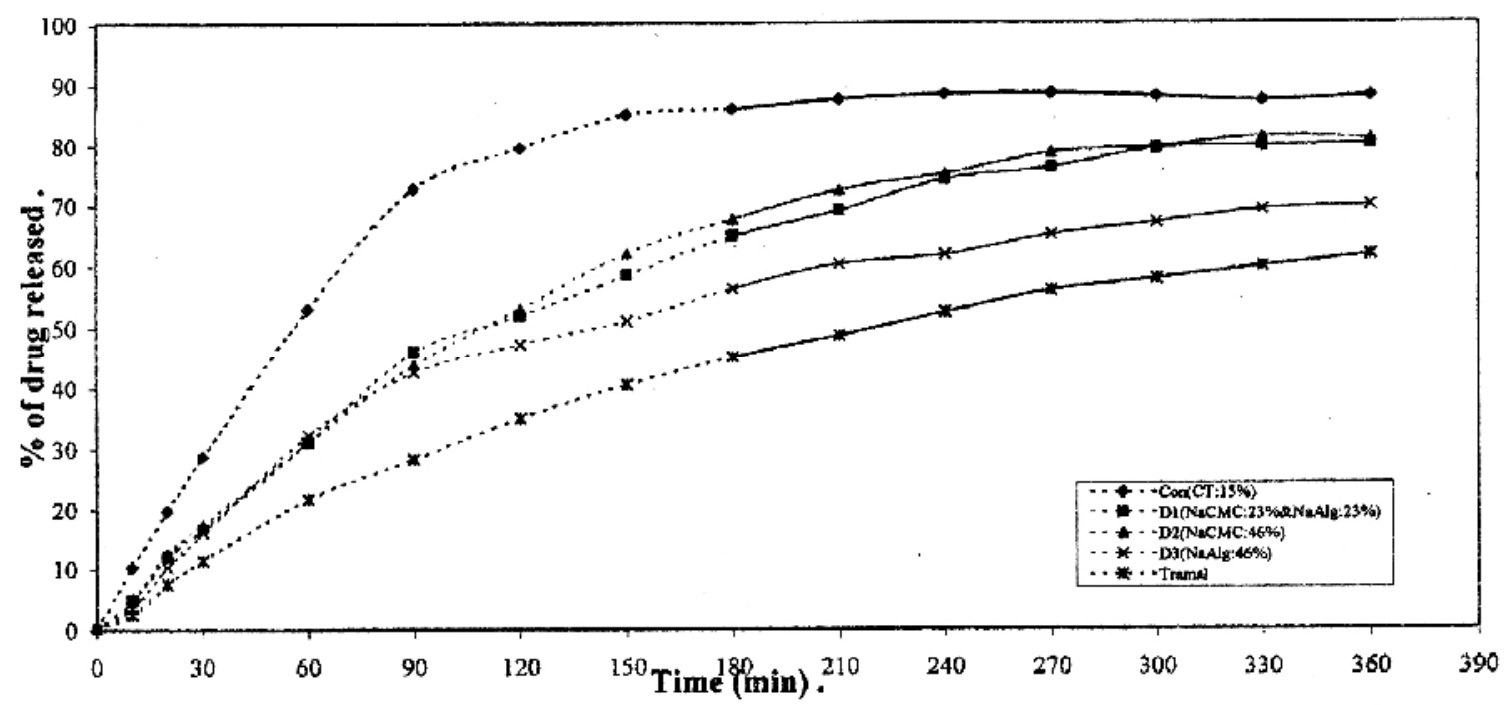

Fig. 8: Release profiles of tramadol from tablets containing compritol \& HPMC with different proportions of $\mathrm{NaCMC}$ and $\mathrm{NaAlg}$ in acid, $\mathrm{pH} \mathrm{1,2} \mathrm{(dotted} \mathrm{line)} \mathrm{then} \mathrm{in} \mathrm{phosphate} \mathrm{buffer,} \mathrm{pH}$ 6.8 (attached line) medium. 


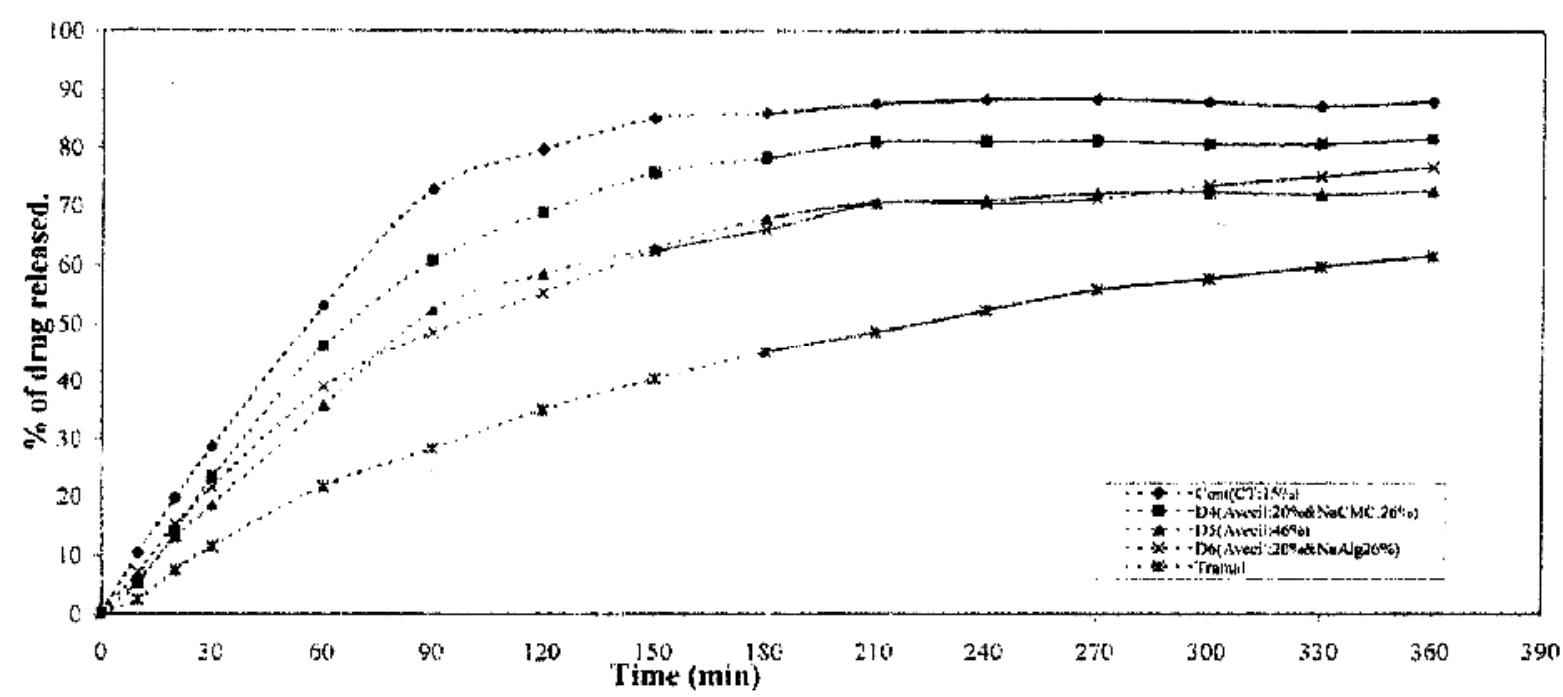

Fig. 9: Release profiles of tramadol from tablets containing compritol \& HPMC with different proportions of Avicel, NaCMC and NaAlg in acid, $\mathrm{pH}$ 1,2 (dotted line) then in phosphate buffer, pH 6.8 (attached line) medium.

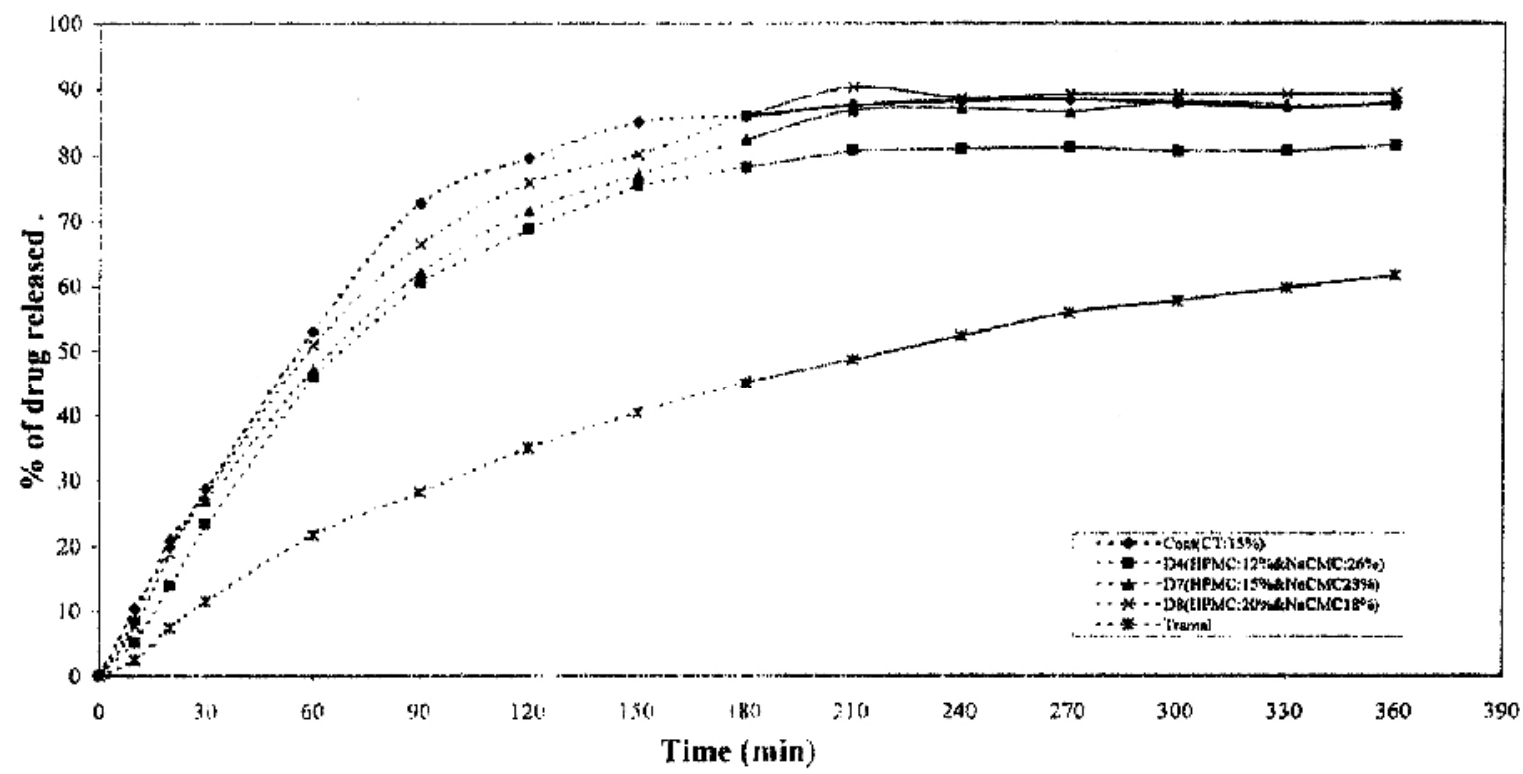

Fig. 10: Effect of increasing HPMC proportions (with decreasing NaCMC) on the release of tramadol from the prepared tablets in acid, $\mathrm{pH} 1.2$ (dotted line) then in phosphate buffer, $\mathrm{pH} 6.8$ (attached line) medium. 


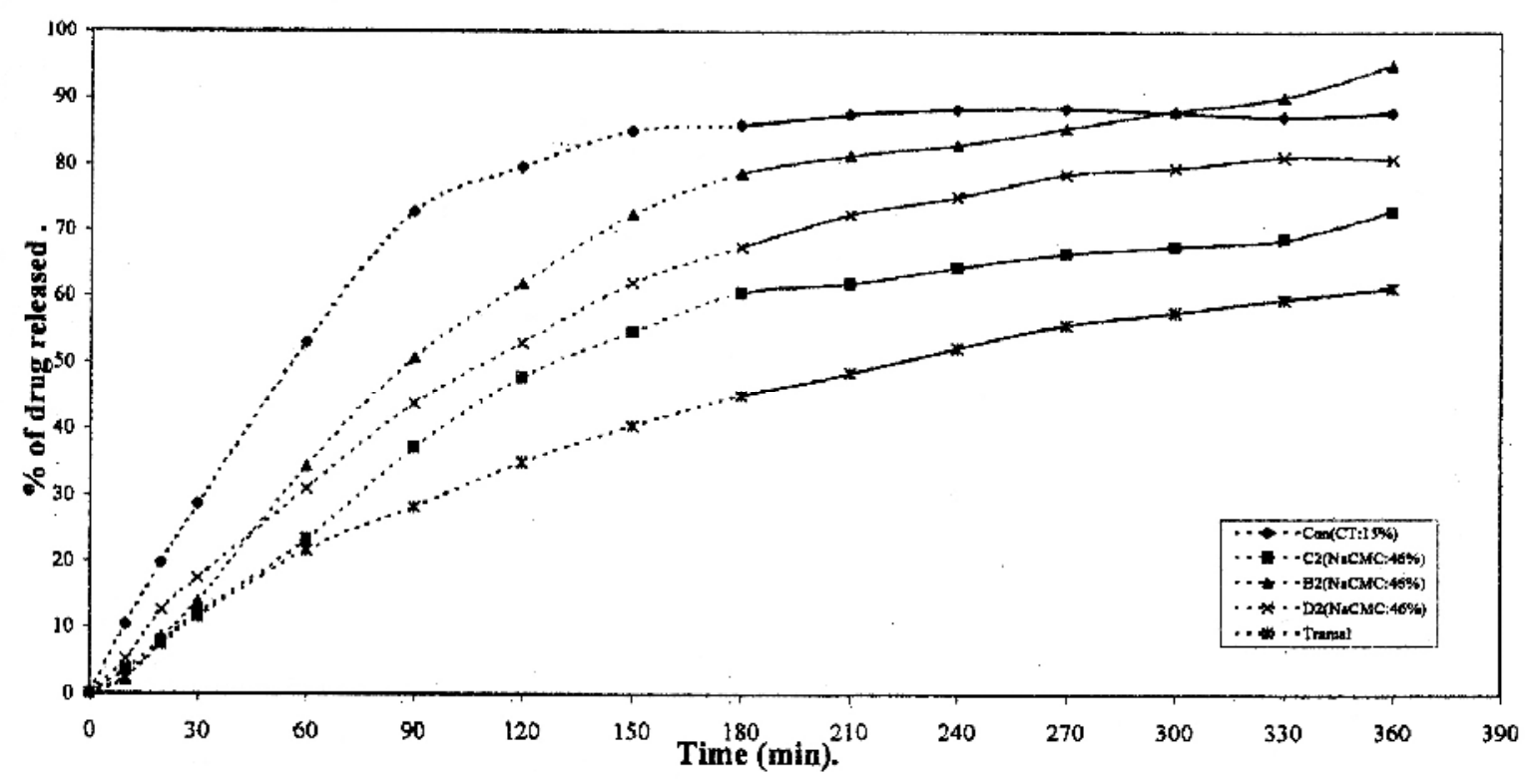

Fig. 11: Effect of adding NaCMC (46\%) alone on the release of tramadol tablets containing each sustaining excipient in acid, pH 1.2 (dotted line) then in phosphate buffer, pH 6.8 (attached line) medium.

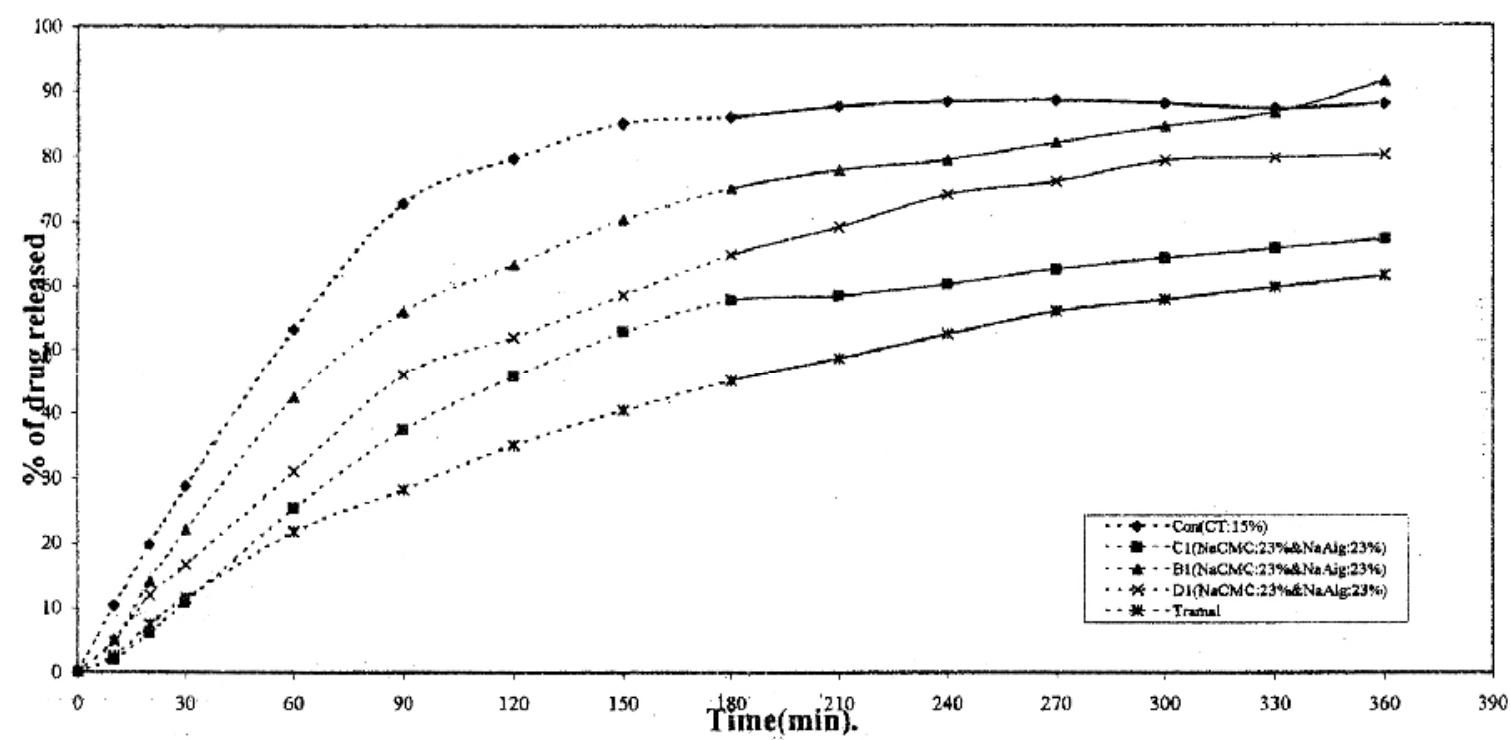

Fig. 12: Effect of adding equal proportions of NaCMC \& NaAlg (23\%) on the release of tramadol tablets containing each sustaining excipient in acid, $\mathrm{pH} 1.2$ (dotted line) then in phosphate buffer, $\mathrm{pH} 6.8$ (attached line) medium. 


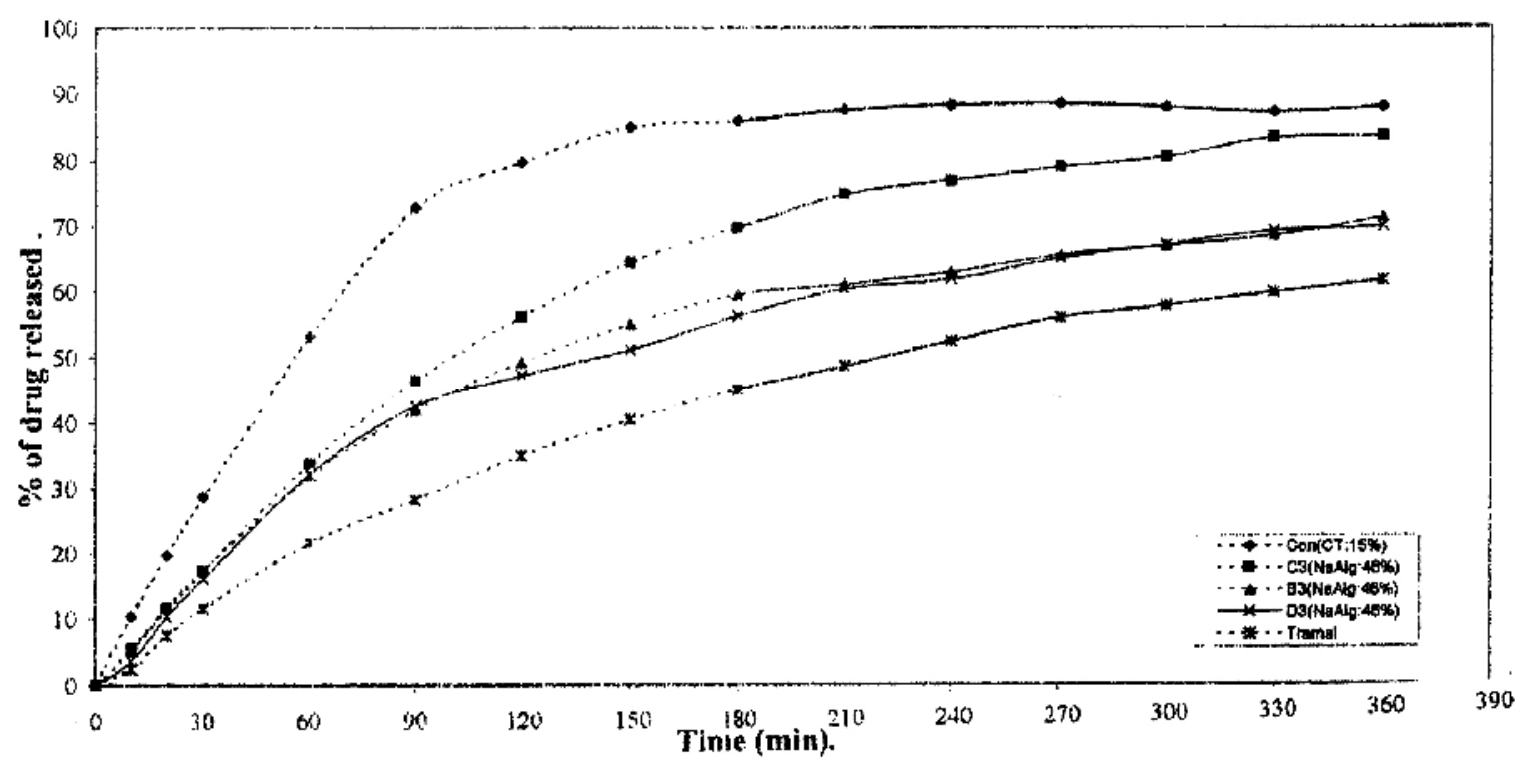

Fig. 13: Effect of adding NaAlg (46\%) alone on the release of tramadol tablets containing each sustaining excipient in acid, $\mathrm{pH} 1.2$ (dotted line) then in phosphate buffer, $\mathrm{pH} 6.8$ (attached line) medium.

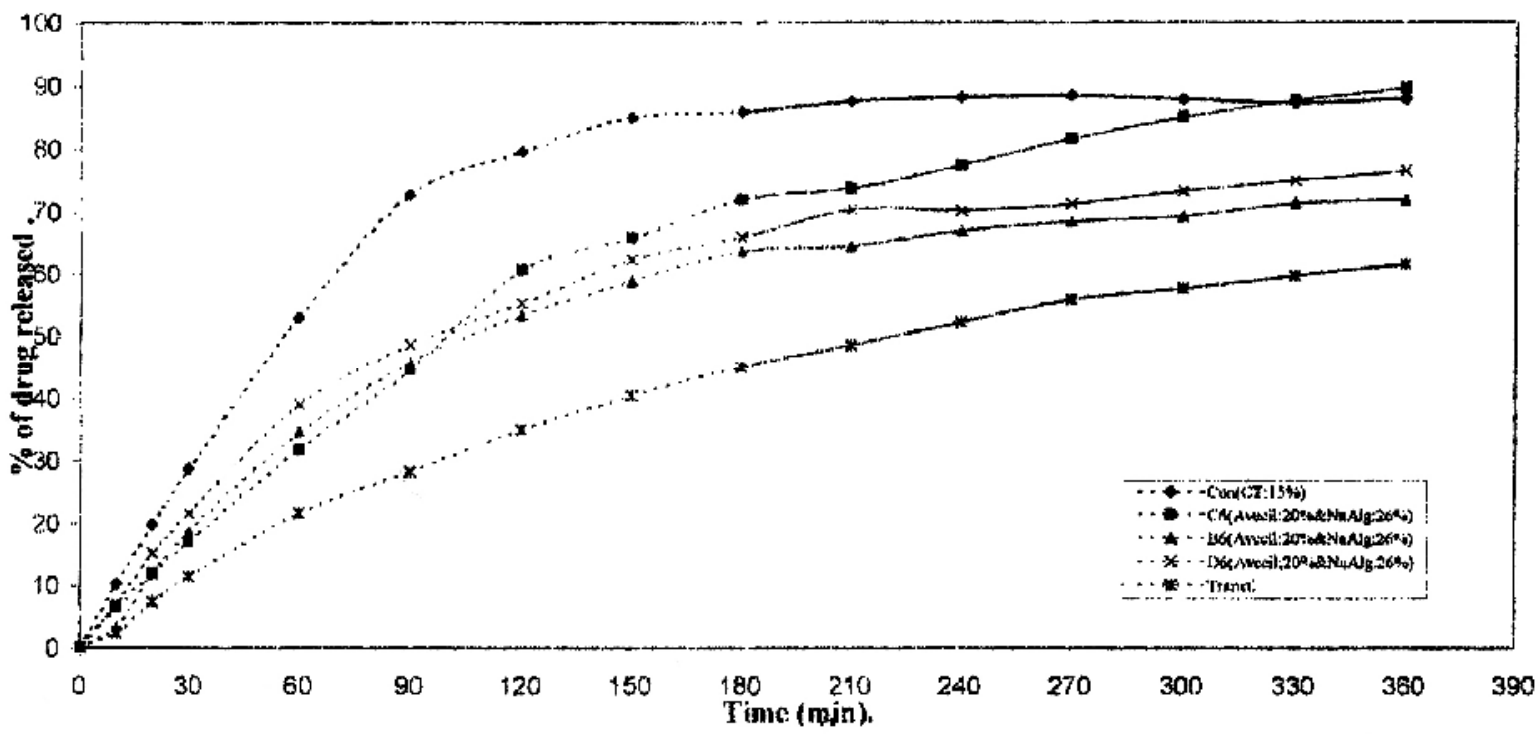

Fig. 14: Effect of adding NaAlg (26\%) alone on the release of tramadol tablets containing Avicel (20\%) with each sustaining excipient in acid, $\mathrm{pH} 1.2$ (dotted line) then in phosphate buffer, pH 6.8 (attached line) medium. 


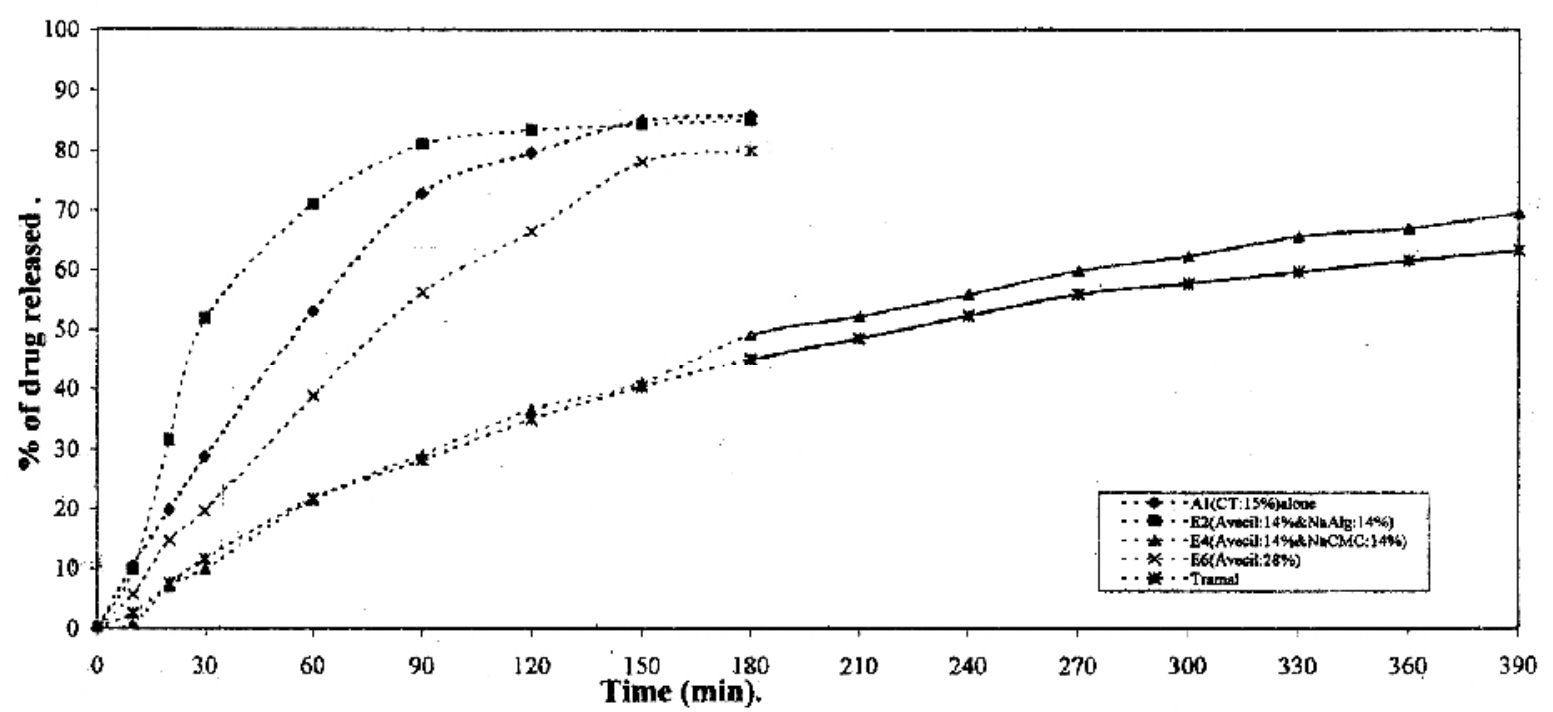

Fig. 15: Release profiles of tramadol from tablets $(250 \mathrm{mg})$ containing commpritol \& HPMC with different proportions of Avicel, NaCMC and NaAlg in acid, $\mathrm{pH} 1.2$ (dotted line) then in phosphate buffer, pH 6.8 (attached line) medium.

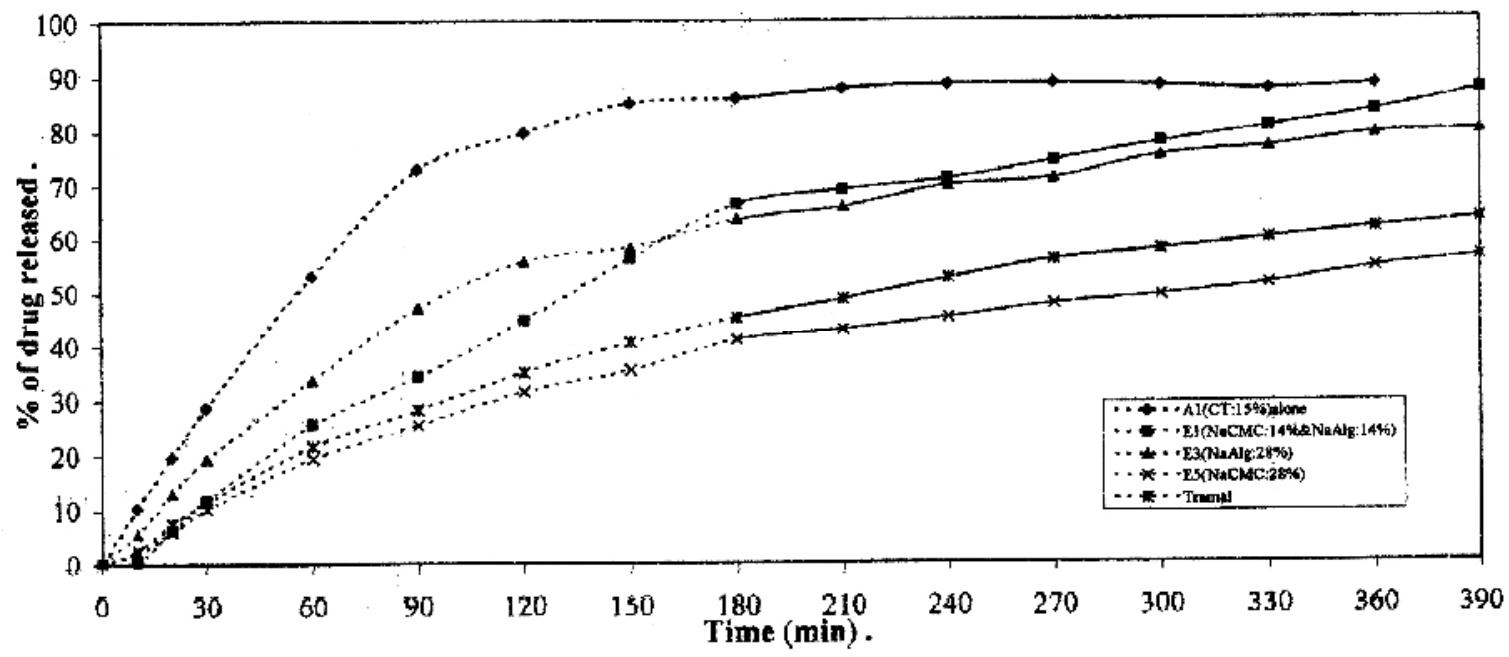

Fig. 16: Release profiles of tramadol from tablets $(250 \mathrm{mg})$ containing commpritol \& HPMC with different proportions of NaCMC and NaAlg in acid, $\mathrm{pH} 1.2$ (dotted line) then in phosphate buffer, pH 6.8 (attached line) medium. 
Table 8: Release kinetics of the prepared tablets.

\begin{tabular}{|c|c|c|c|c|c|c|}
\hline \multirow{2}{*}{ Formula } & \multicolumn{3}{|c|}{ Acidic medium ( $\mathrm{pH}$ 1.2) } & \multicolumn{3}{|c|}{ Phosphate buffer medium (PH 6.8) } \\
\hline & $\mathrm{n}^{*}$ & $\mathrm{~K}$ & $\mathrm{r}$ & $\mathrm{N}$ & $\mathrm{k}$ & $\mathrm{r}$ \\
\hline A1 & 1.5003 & 0.1640 & 0.9840 & --- & --- & -- \\
\hline A2 & 1.3247 & 0.3563 & 0.9821 & -- & -- & -- \\
\hline A3 & 1.1846 & 0.4694 & 0.0788 & -- & -- & -- \\
\hline A4 & 1.0553 & 0.7184 & 0.9932 & -- & -- & -- \\
\hline B1 & 1.0701 & 1.3609 & 0.9808 & 1.0035 & 12.2459 & 0.9880 \\
\hline B2 & 0.7972 & 4.3416 & 0.9837 & 1.9778 & 0.6489 & 0.9980 \\
\hline B3 & 1.1769 & 1.2091 & 0.9898 & 0.8885 & 20.2053 & 0.9966 \\
\hline B4 & 1.0780 & 1.3348 & 0.9894 & -- & -- & -- \\
\hline B5 & 1.2546 & 0.7223 & 0.9849 & 0.7604 & 31.5646 & 0.9571 \\
\hline B6 & 1.0042 & 2.1008 & 0.9742 & 0.7515 & 31.3443 & 0.9736 \\
\hline B7 & 1.0149 & 1.9828 & 0.9839 & 1.5109 & 2.0875 & 0.9888 \\
\hline B8 & 0.9523 & 2.5723 & 0.9755 & 1.1760 & 6.1547 & 0.9961 \\
\hline $\mathrm{C} 1$ & 0.8470 & 4.6759 & 0.9888 & 0.6762 & 34.7564 & 0.9899 \\
\hline $\mathrm{C} 2$ & 0.9993 & 2.6412 & 0.9976 & 0.8683 & 20.7154 & 0.9887 \\
\hline $\mathrm{C} 3$ & 1.1158 & 1.3529 & 0.9952 & 1.6824 & 2.0591 & 0.9939 \\
\hline $\mathrm{C} 4$ & 0.9250 & 0.5970 & 0.8354 & -- & -- & -- \\
\hline $\mathrm{C} 5$ & 1.2423 & 0.5957 & 0.9963 & 1.1872 & 15.4596 & 0.9643 \\
\hline C6 & 1.2450 & 0.8126 & 0.9962 & 0.7640 & 17.7202 & 0.9901 \\
\hline C7 & 0.5261 & 2.6962 & 0.9860 & -- & -- & -- \\
\hline $\mathrm{C} 8$ & 0.7045 & 1.1166 & 0.9350 & -- & -- & -- \\
\hline D1 & 1.1065 & 1.4942 & 0.9904 & 1.3182 & 3.9190 & 0.9686 \\
\hline D2 & 1.1366 & 1.3027 & 0.9936 & 1.5081 & 2.7347 & 0.9931 \\
\hline D3 & 1.0468 & 2.0307 & 0.9790 & 1.3422 & 5.1505 & 0.9865 \\
\hline D4 & 1.0336 & 1.4683 & 0.9790 & -- & -- & -- \\
\hline D5 & 1.1440 & 1.1560 & 0.9895 & 1.2087 & 4.0066 & 0.9557 \\
\hline D6 & 1.2875 & 0.6625 & 0.9882 & 1.6048 & 4.4700 & 0.9161 \\
\hline D7 & 1.2942 & 0.4759 & 0.9851 & 1.3450 & 0.0263 & 0.9372 \\
\hline D8 & 1.1739 & 0.7374 & 0.9815 & 1.2193 & 3.7255 & 0.9670 \\
\hline
\end{tabular}

$* \mathrm{n}=$ Exponent of Equation $(\log \mathrm{Q}=\log \mathrm{K}-\mathrm{n} \log \mathrm{t}), \mathrm{K}=$ Constant, $\mathrm{r}=$ Correlation coefficient. 
Table 9: Release kinetics of the prepared tablets.

\begin{tabular}{|c|c|c|c|c|c|c|}
\hline \multirow{2}{*}{ Formula } & \multicolumn{3}{|c|}{ Acidic medium $(\mathrm{pH} 1.2)$} & \multicolumn{3}{c|}{ Phosphate buffer medium (PH 6.8) } \\
\cline { 2 - 7 } & $\mathrm{n} *$ & $\mathrm{~K}$ & $\mathrm{r}$ & $\mathrm{n}$ & $\mathrm{k}$ & $\mathrm{r}$ \\
\hline $\mathrm{E} 1$ & 0.6016 & 10.5552 & 0.9481 & 0.9132 & 13.4488 & 0.9969 \\
\hline E2 & 1.0660 & 0.6974 & 0.9324 & --- & --- & --- \\
\hline E3 & 1.1815 & 1.0716 & 0.9879 & 0.9785 & 11.800 & 0.9868 \\
\hline E4 & 0.7190 & 8.1069 & 0.9523 & 1.0196 & 8.9783 & 0.9947 \\
\hline E5 & 0.9717 & 4.0591 & 0.9849 & 0.91176 & 17.0056 & 0.9984 \\
\hline E6 & 1.0762 & 1.3079 & 0.9911 & --- & --- & --- \\
\hline Cont. (TL) & 1.7288 & 0.0154 & 0.2408 & --- & --- & -- \\
\hline TL + CT & 1.2443 & 0.5027 & 0.9945 & --- & --- & --- \\
\hline Tramal & 1.2240 & 1.5671 & 0.9978 & 1.1360 & 6.7757 & 0.9917 \\
\hline
\end{tabular}

$*_{\mathrm{n}}=$ Exponent of Equation $(\log \mathrm{Q}=\log \mathrm{K}-\mathrm{n} \log \mathrm{t}), \mathrm{K}=$ Constant, $\mathrm{r}=$ Correlation coefficient.

\section{CONCLUSION}

From the results of this investigation it could be concluded that:

1- All the prepared tablets successfully fulfill the USP/NF ${ }_{1995}$ requirements with respect to friability values, the uniformity of weight and diameter. The tensile strength $\left(T_{\mathrm{s}}\right)$ values were found to be suitable for all the prepared tablets.

2- Compritol is more effective for sustaining the tramadol release at 12 and $15 \%$ concentrations. PT showed the most sustaining effect when included with $\mathrm{NaCMC}$ either alone or with $\mathrm{NaAlg}$, followed by HPMC then PC. However, the later two materials showed better sustaining properties with NaAlg alone than with $\mathrm{NaCMC}$.

3- Smaller tablets $(250 \mathrm{mg})$ containing NaCMC alone showed the most sustaining effect (more than $\mathrm{Tramal}^{\circledR}$ ) followed by those including $\mathrm{NaCMC}$ and Avicel.

4- Generally, the release of tramadol $\mathrm{HCl}$ from all formulations in acid medium $(0.1$ $\mathrm{N} \mathrm{HCl}, \mathrm{pH}$ 1.2) was pronouncedly more rapid than in phosphate buffer $(\mathrm{pH} 6.8)$. Either in acid or phosphate buffer medium the release of tramadol was through the recommended zero-order release kinetics.

\section{REFERENCES}

1- S. K. Baveja, K. V. Ranga Rao, A. Singh and V. K. Gombar, Int. J. Pharm., 41, 5562, (1988).

2- L. C. Feely and S. S. Davis, ibid., 41, 8390 (1988).

3- L. C. Feely S. S. and Davis, ibid, 44, 131139 (1988).

4- J. L. Ford, K. Mitchell, D. Sawh, S. Ramdour, D. J. Armstrong, P. N. C. Elliott, C. Rostron and J. E. Hogan, ibid. 71, 213-221 (1991).

5- S. I. Abdelrahman, S. I. Saleh, S. M. Ahmed, A. E. Abutaleb and A. M. Aly, S.T.P. Pharma Science, 3 (5), 386-390 (1993).

6- S. Malamataris, T. Karidas and P. Goidas, Int. J. Pharm. 103, 205-215 (1994).

7- M. J. Vazquez, J. L. Gomez-Amoza, R. Martinez-Pacheco, C. Souto and A. Concheiro, Drug Dev. Ind. Pharm. 21 (16), 1859-1874 (1995).

8- P. J. Sheskey, R.T. Robb, R. D. Moore and B. M. Boyce, ibid. 21 (19) 2151-2165 (1995).

9- A. S. Aly, A. M. Aly and F. A. Mohamed, Bull. Pharm. Sci., Assiut. University, 20 (2), 141-146 (1997).

10- A. M. Aly, 36 ${ }^{\text {th }}$ Science Week, Aleppo University, Syria 2-7 November (1996). 
11- A. M. Aly, Jordan Journal of Applied Sciences, 2 (1), 64-82 (1999).

12- A. M. Aly, $37^{\text {th }}$ Science Week, (1-6, Nov. 1997), 4 (2),.447-453 (1997).

13- A. M. Aly, Ass. Univ. Bull. Environ. Res., 2 (1), 45-53 (1999).

14- M. O. Ahmed and A. M. Aly, Bull. Pharm. Sci., Assiut. University, 24 (1), 73-82 (2001).

15- R. W. Korsmeyer, R. Gurny, D. E. Burip. and N. A. Peppas, Int. J. Pharm., 15, 25-35 (1983).

16- J. L. Ford, M. H. Rubinstein, F. McCaul, J. E. Hogan and P. J. Edgar, ibid., 40, 223, 234 (1987).

17- S. K. Baveja, K. V. Ranga Rao and P. Devi., ibid. 39, 39-45 (1987).
18- P. Catellani, G. Vaona, P. Please and P. Colombo, Acta Pharm. Technol., 34 (1), 38-41 (1988).

19- J. Siepmann, K. Podual, M. Sriwongjanya, N. A. Peppas and R. A. Bodmeier, J. Pharm. Sci, 88 (1), 65-72 (1999).

20- A. R. Rajabi-Siahboomi, R. W. Bowtell, P. Mansfield, M. C. Davies and C. D. Melia, Pharm. Res., 13 (3), 376-80 (1996).

21- T. D. Reynolds, S. H. Gehrke, A. S. Hussain and L. S. Shenouda, J. Pharm. Sci., 87 (9), 1115-23 (1998).

22- R. T. Ju, P. R. Nixon, M. V. Patel and D. M. Tong, ibid, 84 (12), 1464-77 (1995).

23- Lexi-comp Inc, Poisoning and Toxicology Handbook (1995-1997) on CD ROM. 